The daytime mixing layer during MILAGRO

W. J. Shaw et al.

\title{
The daytime mixing layer observed by radiosonde, profiler, and lidar during MILAGRO
}

W. J. Shaw ${ }^{1}$, M. S. Pekour ${ }^{1}$, R. L. Coulter ${ }^{2}$, T. J. Martin ${ }^{2}$, and J. T. Walters ${ }^{3}$

${ }^{1}$ Pacific Northwest National Laboratory, Richland, Washington, USA

${ }^{2}$ Argonne National Laboratory, Argonne, Illinois, USA

${ }^{3}$ University of Alabama in Huntsville, Huntsville, Alabama, USA

Received: 28 September 2007 - Accepted: 5 October 2007 - Published: 19 October 2007

Correspondence to: W. J. Shaw (will.shaw@pnl.gov)

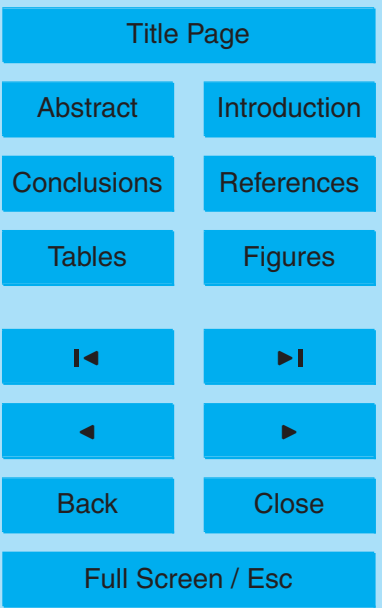

Printer-friendly Version

Interactive Discussion 


\section{Abstract}

During the MILAGRO campaign centered in the Mexico City area, Pacific Northwest National Laboratory (PNNL) and Argonne National Laboratory (ANL) operated atmospheric profiling systems at Veracruz and at two locations on the Central Mexican

5 Plateau in the region around Mexico City. These systems included radiosondes, wind profilers, a sodar, and an aerosol backscatter lidar. An additional wind profiler was operated by the University of Alabama in Huntsville (UAH) at the Mexican Petroleum Institue (IMP) near the center of Mexico City. Because of the opportunity afforded by collocation of profilers, radiosondes, and a lidar, and because of the importance of boundary layer depth for aerosol properties, we have carried out a comparison of mixing layer depth as determined independently from these three types of measurement systems during the campaign. We have then used results of this comparison and additional measurements to develop a detailed description of the daily structure and evolution of the boundary layer on the Central Mexican Plateau during MILAGRO.

15 Our analysis indicates that the profilers were more consistently successful in establishing the mixing layer depth during the daytime. The boundary layer growth was similar at the three locations, although the mixing layer tended to be slightly deeper in the afternoon in central Mexico City. The sodar showed that convection began about an hour after sunrise. Maximum daily mixing layer depths always reached $2000 \mathrm{~m}$ a.g.l. and frequently extended to $4000 \mathrm{~m}$. The rate and variability of mixing layer growth was essentially the same as that observed during the IMADA-AVER campaign in the same season in 1997. This growth did not seem to be related to whether deep convection was reported on a given day.

Wind speeds within the boundary layer exhibited a daily low-altitude maximum in the late afternoon with lighter winds aloft, consistent with previous reports of diurnal regional circulations. Norte events, which produced high winds at Veracruz, did not appreciably modulate the winds on the plateau. Finally, despite the typically dry conditions at the surface, radiosonde profiles showed that relative humidity often exceeded

The daytime mixing layer during MILAGRO

W. J. Shaw et al.

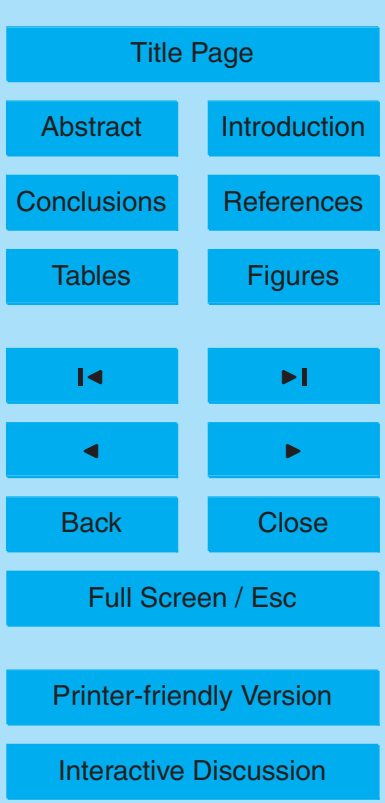


$50 \%$ in the early morning and in the upper part of the boundary layer. This suggests that aerosol particles would have experienced hygroscopic growth within the boundary layer on many days.

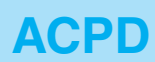

\section{Introduction}

5 During March 2006 scientists primarily from the United States and Mexico executed a massive field measurement campaign in Mexico to study atmospheric chemistry and the associated atmospheric aerosol. Termed the "Megacity Initiative: Local and Global Research Observations" (MILAGRO), the campaign actually comprised four separate major research programs. The Mexico City Metropolitan Area-2006 (MCMA-2006) Ex10 periment focused on air quality issues in the Mexico City area. The Megacity Aerosol Experiment (MAX-Mex) explored the transport and chemical and optical transformation of atmospheric particulates. The Megacity Impacts on Regional and Global Environments (MIRAGE) program also addressed the transformation of pollutants and their effects on regional and global scales. Finally, the Intercontinental Chemical Transport 15 Experiment (INTEX-B) emphasized the effects of long-range transport of pollutants on atmospheric radiation and climate.

To understand the properties and effects of atmospheric particulate matter, it is necessary to understand its distribution in the atmospheric column. This in turn requires good information about the dynamic and thermodynamic structure of the atmospheric boundary layer ( $A B L)$. To contribute to this information during the MILAGRO campaign centered in the Mexico City area, Pacific Northwest National Laboratory (PNNL) and Argonne National Laboratory (ANL) operated atmospheric profiling systems at Veracruz and at two locations on the Central Mexican Plateau in the region around Mexico City. These systems included radiosondes, wind profilers, a sodar, and an aerosol backscatter lidar. An additional wind profiler was operated by the University of Alabama in Huntsville (UAH) at the Mexican Petroleum Institute (IMP) near the center of Mexico City.

The daytime mixing layer during MILAGRO

W. J. Shaw et al.

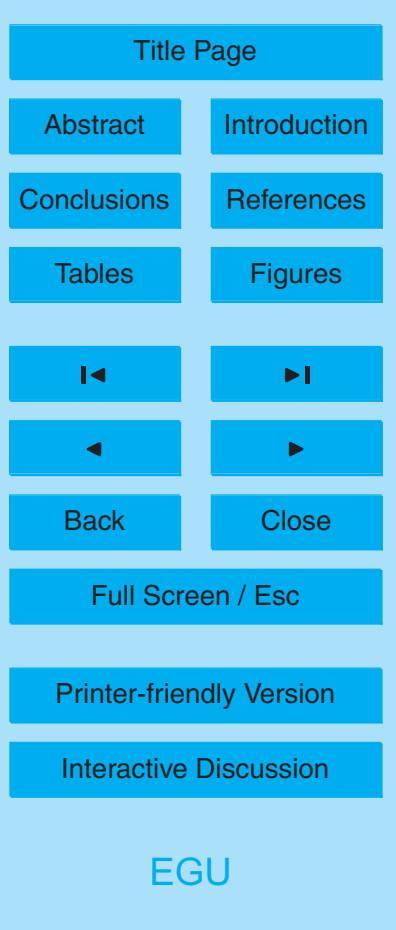


The depth of the mixing layer is a critical factor in determining the concentration of gaseous emissions and particulate matter at the surface (e.g., Berkowitz and Shaw, 1997). When the mixing layer is shallow, as is often the case overnight and in the early morning, material emitted from sources at the surface remains near the surface, and 5 concentrations can become quite large, particularly if winds are light (e.g., Fast et al., 2000). As the deepening ABL mixes material away from the surface during the daytime, concentrations of both particulate matter and its chemical precursors decrease. This effect is substantial, since the mixing layer at night may be only a few tens of meters deep, while during the daytime as our data will show in agreement with pre10 vious studies, the depth of the mixing layer above the Central Mexican Plateau can routinely exceed $3000 \mathrm{~m}$ in the afternoon. In a further enhancement of the dilution of a deepening boundary layer, convective clouds with bases at the top of the ABL also serve to remove aerosol particles from the boundary layer and inject them into the free atmosphere above.

15 An additional effect of varying mixing layer depth is the resulting variation of relative humidity in the ABL. Owing to the decrease of temperature with height the relative humidity tends to increase with height in the mixing layer. Because of the hygroscopic nature of many aerosol particles, this variation of relative humidity in turn modifies the particle size distribution over the depth of the ABL. Knowledge of the boundary layer humidity structure is therefore important for those who wish to compare airborne and surface measurements of aerosol physical properties or who wish to compare surface aerosol and atmospheric radiation measurements.

There has been much discussion in the literature of methods by which the depth of the mixing layer may be inferred from various atmospheric measurements. Because of the opportunity afforded by collocation of profilers, radiosondes, and a lidar, and because of the importance that we have already noted of boundary layer depth on aerosol properties, we have carried out a comparison of mixing layer depth as determined independently from these three types of measurement systems during the campaign. We have then used results of this comparison and additional measurements to develop a

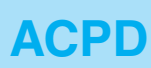

7, 15025-15065, 2007

The daytime mixing layer during MILAGRO

W. J. Shaw et al.

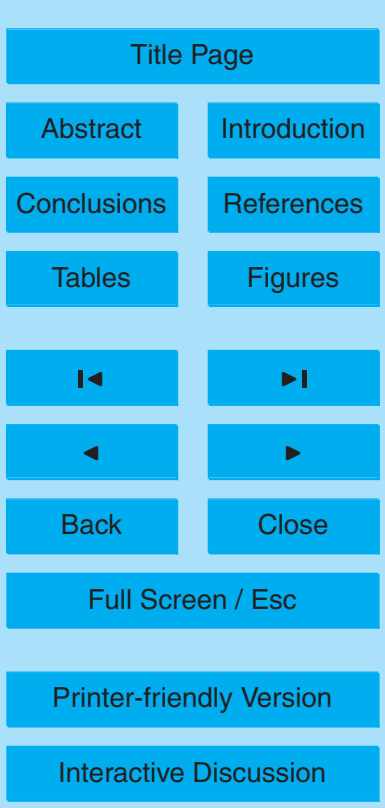

EGU 
detailed description of the daily structure and evolution of the boundary layer on the Central Mexican Plateau during MILAGRO.

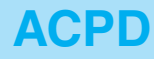

7, 15025-15065, 2007

\section{The observations}

\subsection{Measurement environment}

5 Surface-based measurements during MILAGRO were concentrated at three field sites. Because of the importance of atmospheric transport in the study of particulates, these sites came to be called T0, T1, and T2 to indicate sequential arrival times for air parcels under prevailing wind conditions. In particular, the locations for T1 and T2 were selected to allow study of the evolution of properties of relatively fresh particles due to 10 chemical aging as described in Doran et al. (2007). Figure 1 shows the location of these sites. The data that we will emphasize in this paper were gathered at T1 and T2, although we also include mixing depth measurements from T0, which was located at IMP in central Mexico City. T1 was just north of Mexico City (at Universidad de Tecámac) and is on the northeastern edge of the urban area. The elevation of T1 is approximately $2300 \mathrm{~m} \mathrm{MSL}$. T2 was located approximately $50 \mathrm{~km}$ to the north at Rancho la Bisnaga, a privately owned ranch at an elevation of approximately $2500 \mathrm{~m} \mathrm{MSL}$.

Annually, Mexico City experiences a dry season that extends on average from October through March or April (e.g., Juaregui, 1997). From May through September, deep tropical convection and an associated significant increase in precipitation are common. The MILAGRO campaign was planned to occur near the end of the dry season. Fast et al. (2007) have described the general weather conditions of MILAGRO. In general, at the beginning of the campaign, conditions remained quite dry. By the end of the campaign, clear mornings followed by occasionally deep afternoon convection were common. On one evening we observed localized hail that accumulated to a depth greater than $15 \mathrm{~cm}$ on a highway near Pachuca about $15 \mathrm{~km}$ northeast of T2. (The estimate is based on the depth of the hail exceeding vehicular rim heights above the

\section{The daytime mixing layer during MILAGRO}

W. J. Shaw et al.

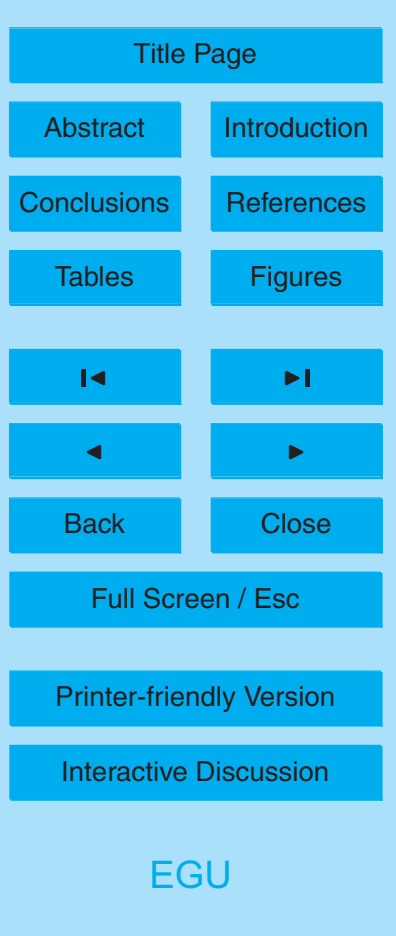


pavement.)

\subsection{Instrumentation}

ANL operated instrument systems at T1 that included a micropulse lidar, a $915 \mathrm{MHz}$ wind profiling radar, a mini-sodar, and a Vaisala rawinsonde system. At T2, PNNL 5 operated systems that included a $915 \mathrm{MHz}$ wind profiler and a Vaisala rawinsonde system. A sodar had also been planned for T2, but a critical signal cable was lost en route to Mexico and could not be replaced by the end of the MILAGRO campaign. UAH operated the $915 \mathrm{MHz}$ radar that is part of their Mobile Integrated Profiling System (MIPS) on a rooftop at T0. These instrument systems are summarized in Table 1.

The lidar was a micropulse system operating at a wavelength of $573 \mathrm{~nm}$. The pulse rate was $2500 \mathrm{~s}^{-1}$, and the range resolution was $15 \mathrm{~m}$. The beam was directed vertically, and the system measured the intensity of backscattered radiation from $15 \mathrm{~m}$ to $60 \mathrm{~km}$ above ground level (a.g.l.); however, only the data to approximately $6 \mathrm{~km}$ a.g.l. are used in this study. Radiation measurements at a delay time corresponding to a range of 45 to $55 \mathrm{~km}$ were used to evaluate the background radiation.

The wind profilers at T1 and T2 were functionally identical $915 \mathrm{MHz}$ systems set to identical sampling configurations. The radars were operated in a single five-beam mode with no pulse coding. The pulse length was $2800 \mathrm{~ns}$, which yielded a range resolution of $400 \mathrm{~m}$; the data were oversampled to $192.5 \mathrm{~m}$ range gates. The dwell time for each beam was $19.6 \mathrm{~s}$, and consensus wind averages were calculated each half hour. This yielded typically 15-16 samples from which to form each consensus average. Wind measurements began at $206 \mathrm{~m}$ a.g.l., and the maximum possible height was $4825 \mathrm{~m}$ a.g.l. The maximum usable height for wind measurements depended on atmospheric conditions and was almost always less than $4825 \mathrm{~m}$. The profilers also provided measurements of the signal-to-noise ratio (SNR) for each range gate, which we have used to infer mixing layer depth as described in Sect. 3. The UAH radar is physically equivalent to the radars at $\mathrm{T} 1$ and $\mathrm{T} 2$, but some settings, including the beam sequence, differed from the other two during MILAGRO. This operational difference 15030

The daytime mixing layer during MILAGRO

W. J. Shaw et al.

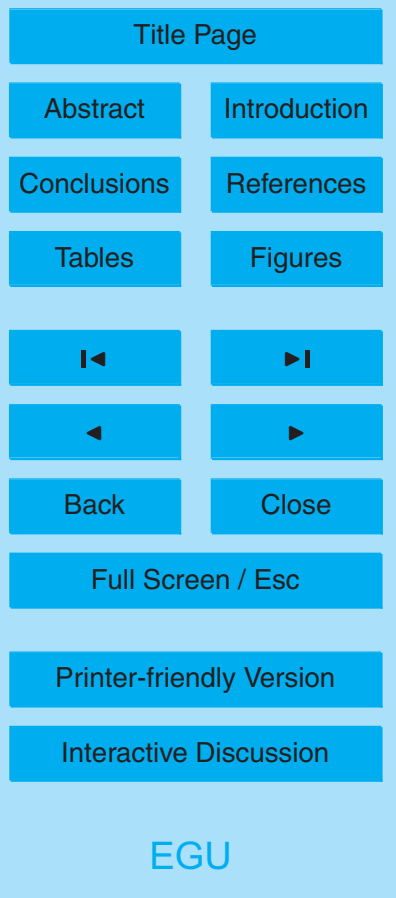


had no practical effect on how we treated its data for purposes of this paper.

Wind data from all three profilers were processed using the NCAR Improved Moment Algorithm (NIMA; Morse et al., 2002). This algorithm uses a combination of pattern recognition and fuzzy logic to better identify Doppler spectral peaks when the signal5 to-noise ratio is less than ideal. NIMA can do this effectively in many cases when the native peak selection algorithm fails to correctly identify the Doppler peak. It thus usually provides a more robust consensus wind estimate. NIMA is less successful when there is large shear in the wind profile. We have compared the time-height structure of winds with and without NIMA processing and concluded that, for MILAGRO, the NIMA 10 winds are generally superior when the NIMA internal confidence parameter is 0.5 or greater. Profiler winds reported in this paper have been processed by NIMA.

Argonne also operated a high-frequency sodar at T1. This system is described in detail in Coulter and Martin (1986). The sodar was operated in a three beam mode at an acoustic frequency of $4500 \mathrm{~Hz}$ and an operational range from 15 to $200 \mathrm{~m}$ a.g.l. with

$155 \mathrm{~m}$ resolution. This system filled in winds between the surface and the lowest range gates of the radar to provide a complete wind profile in the lower atmosphere.

The radiosonde systems used at both T1 and T2 were DigiCORA systems manufactured by Vaisala. The target ascent rate was $3-5 \mathrm{~m} \mathrm{~s}^{-1}$. The radiosondes used for most launches were Vaisala's RS-92K units, which use a reflective thermistor for temperature measurements and a capacitance technique for relative humidity, but do not measure wind. On days in which aircraft were intensively sampling the atmosphere around Mexico City, five soundings were made at T1 and three were made at T2. Two of the soundings at $\mathrm{T} 1$ on the intensive days were from rawinsondes (Vaisala RS92GPS), which used the Global Positioning System (GPS) to provide a wind vector profile in addition to the standard thermodynamic variables. On other days, a single thermodynamic sounding was made at each location.
ACPD

7, 15025-15065, 2007

The daytime mixing layer during MILAGRO

W. J. Shaw et al.

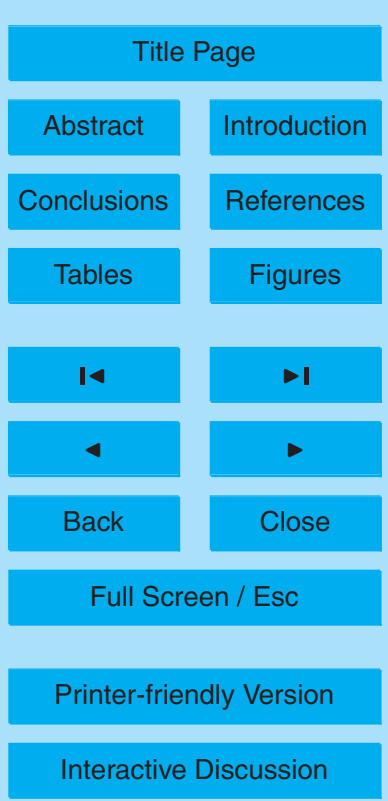




\section{Measuring mixing layer depth}

\subsection{Comparison of measurement methods}

There have been numerous evaluations of techniques for measuring the depth of the boundary layer from radiosondes, sodars, wind profilers and lidars. Most of these re-

5 ports involve the comparison of pairs of these four systems. For example, Angevine et al. (1994), Grimsdell and Angevine (1998), and Heo et al. (2003) compared boundary layer depths derived from radiosondes and wind profilers. White et al. (1999) compared these quantities derived from profilers and an airborne lidar. Van Pul et al. (1994) and Cooper and Eichinger (1994) compared ABL depths from a lidar and radiosondes, and 10 Coulter and Martin (1986) performed a three-way comparison among radiosondes, a lidar, and a sodar. With the collocation of a radiosonde system, a wind profiler, and a lidar at T1, we have the opportunity to simultaneously compare the three primary types of ground-based instruments that can be used to detect the top of deep convective boundary layers. Since it is particularly useful in defining stable and shallow convective boundary layers, we also include in our discussion the sodar that operated at T1. Instruments discussed in the paper are summarized in Table 1.

Because of variations in the literature, we should clarify some concepts and our usage of terminology before we discuss our specific approach to determining boundary layer depth from the various devices. When we use the term "boundary layer" (or $A B L$ ), 20 we refer to the layer in contact with the earth's surface through which material and momentum are being actively mixed by more or less continuous turbulence. Under thermodynamically stable stratification at night, the turbulence may become intermittent. With solar heating of the surface in the daytime, the turbulence is generally continuous and vigorous. It is this active mixing that under convective conditions creates the clas25 sic profile of scalar variables that are nearly uniform with height. This mixing process also generates the capping inversion at the top of the mixed layer. However, neutrally stratified mixed layers and stably stratified inversions have no inherent tendency to "unmix", and previously turbulent near-neutral layers can retain their mean well-mixed

The daytime mixing layer during MILAGRO

W. J. Shaw et al.

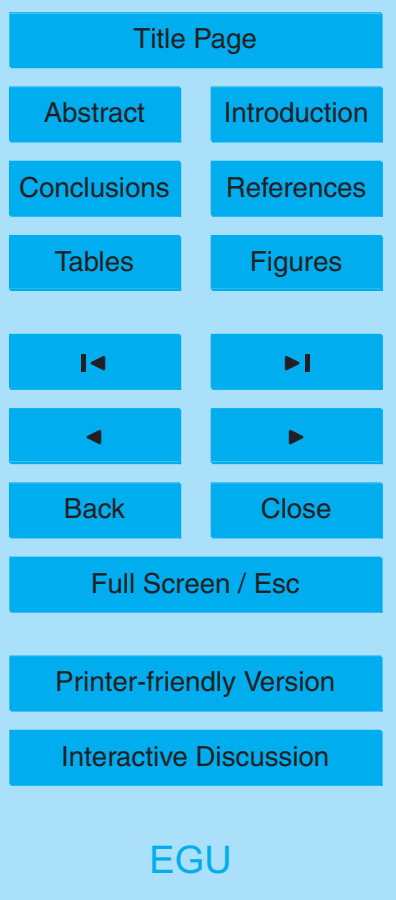


characteristics long after turbulent mixing has ceased. This can lead to significant differences between $A B L$ depths estimated from radiosondes and from remote sensing devices. We therefore distinguish between "mixing" and "mixed" layers and take the $A B L$ to be a mixing layer.

5 One of the strong appeals of the remote sensing devices for measuring the boundary layer is the possibility of automating the measurement of $A B L$ depth. The concepts governing the interaction of sound and electromagnetic radiation with the atmosphere are well known, and several authors have described approaches to objectively determining the depth of the mixing layer (e.g., Angevine et al., 1994; White et al., 1999; Bianco 10 and Wilczak, 2002). Automated methods have never been fully reliable, however, because none of these systems responds exclusively to turbulent mixing. Turbulence contributes most prominently to radar and sodar backscatter, but there can be considerable ambiguity in the inferred boundary layer depth. Thus, most researchers resort to subjective selection of the depth of the mixing layer, and we have done so for this 15 analysis. In the remainder of this section we will describe the criteria that we have used to determine the depth of the boundary layer from each of the measurement systems.

\subsubsection{Boundary layer depth from radiosondes}

For radiosondes, the top of the daytime convective boundary layer is frequently identified as the location of the capping inversion, an atmospheric feature produced by the 20 interaction of large-scale subsidence and turbulence. The capping inversion is a distinctive increase in temperature, or at least potential temperature, with height, and it is commonly associated with a similar decrease in humidity. These gradients are frequently quite sharp. The classical schematic of the convective boundary layer has a thin superadiabatic layer at the surface beneath a layer of constant potential tempera25 ture that results from turbulent mixing. Turbulence rapidly dies with height in the stably stratified capping inversion.

Holzworth $(1964,1967)$ suggested that since air parcels in the superadiabatic surface layer will rise to their level of neutral buoyancy, the depth of the convective bound-

The daytime mixing layer during MILAGRO

W. J. Shaw et al.

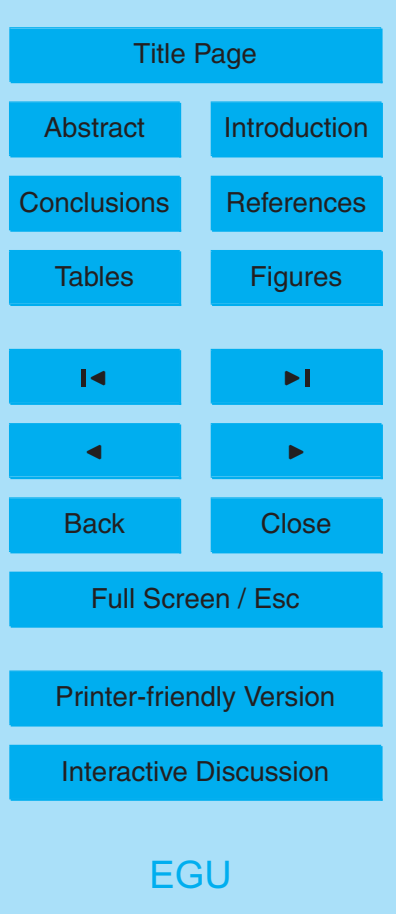


ary layer could be determined by finding the point in the capping inversion that matched the potential temperature of air at the surface. While appealingly simple and objective, Seibert et al. (2000) note that this approach depends heavily on the surface temperature. If the temperature at the surface is overestimated, which can happen for example 5 if the radiosonde temperature sensor absorbs solar radiation without proper ventilation prior to launch, the boundary layer depth will be overestimated.

More often, the depth of the convective boundary layer is identified by inspecting the potential temperature profile for the capping inversion and subjectively selecting an altitude within the inversion that seems appropriate. This approach allows the researcher 10 to apply judgment to the selection that is difficult to replicate with computer code. We have carried out subjective selections of boundary layer depth using a graphical user interface (GUI) that we wrote using MatLab software. This GUI allowed us to choose a primary selection and up to two alternates for boundary layer depth directly from a plot of potential temperature $\theta$ and specific humidity $q$ and, when available, wind speed 15 and direction profiles. For purposes of comparison with other instruments, we have selected the mixing depth from each profile without a priori reference to other instruments or adjacent profiles.

The reason that we provided for alternate selections is that for some sounding profiles there can be more than one plausible choice for the depth of the mixing layer. The mere presence of an inversion above a nearly adiabatic layer does not imply that the adiabatic layer is actively turbulent. At the same time, the passage of a radiosonde in and out of thermals during its ascent through the boundary layer can create temperature jumps in the profile that have the appearance of small inversions. On five occasions, all of which occurred in mid-to-late afternoon, soundings displayed characteristics that did not seem at all consistent with a well-defined boundary layer. Also without a priori reference to other measurements, these sounding were removed from further analysis.

Figure 2 shows an example profile of $\theta$ and $q$ from MILAGRO that illustrates the ambiguity that can occur in the selection of the depth of the mixing layer. There is an

The daytime mixing layer during MILAGRO

W. J. Shaw et al.

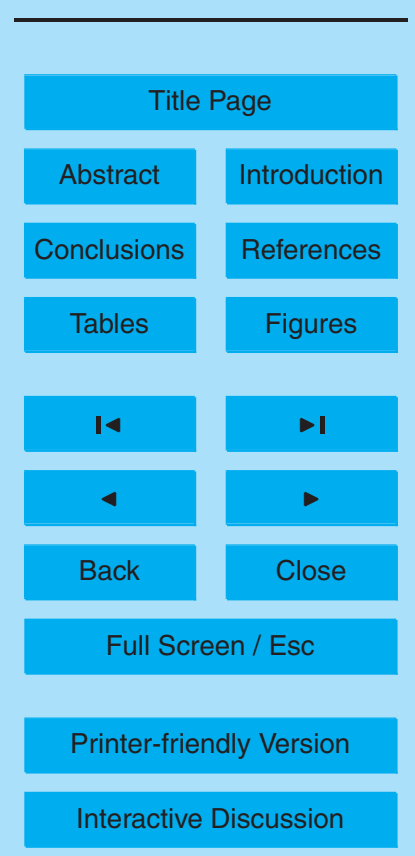


obvious jump in potential temperature near $1500 \mathrm{~m}$ a.g.l. and a corresponding sharp decrease in mixing ratio. However, the mixing ratio profile shows considerable variability above $900 \mathrm{~m}$ that is not consistent with a well mixed layer. Further, there is a small jump in $\theta$ at that altitude and decrease in mixing ratio that could indicate the top of

5 the turbulent layer. The radiosonde was launched at 17:00 UTC (11:00 LT), and at that time either altitude for the top of the mixing layer was plausible. Based on the variability of the mixing ratio above $900 \mathrm{~m}$, we selected the lower level as most likely the top of the mixing layer and the strong inversion near $1500 \mathrm{~m}$ as an alternate choice for this particular sounding. We did not refer to other measurement systems in making our 10 selection. We have followed this approach to estimate boundary layer depths for all of the radiosonde launches from $\mathrm{T} 1$ and $\mathrm{T} 2$.

\subsubsection{Boundary layer depth from lidar}

For lidars, the return signal strength is determined by light scattering by particulate matter. Because surface activities and gases emitted into the boundary layer are primary sources of these particles, they usually occur in much higher concentrations in the boundary layer than above. Thus, the top of the boundary layer is generally taken to be the altitude at which there is a strong decrease in the range-corrected intensity of backscattered light (e.g., Van Pul et al., 1994).

Figure 3 shows a time-height cross section of lidar returns on the same day as the 20 radiosonde ascent in Fig. 2. This figure is typical of lidar returns during MILAGRO. Strong returns from particulate matter in the boundary layer were present during the daytime. The sharp reduction in signal generally delineates the boundary between the mixing layer and the free atmosphere above. This figure suggests rapid growth of the boundary layer in the morning followed by a decrease in depth in the afternoon.

25 There are two other notable features in Fig. 3. Between sunrise and noon (LT), the return shows significant particulate matter in a layer above the newly growing convective boundary layer. This may be material that remained in the layer from the previous day, or it could be new aerosol particles created by photochemical processes. In any

The daytime mixing layer during MILAGRO

W. J. Shaw et al.

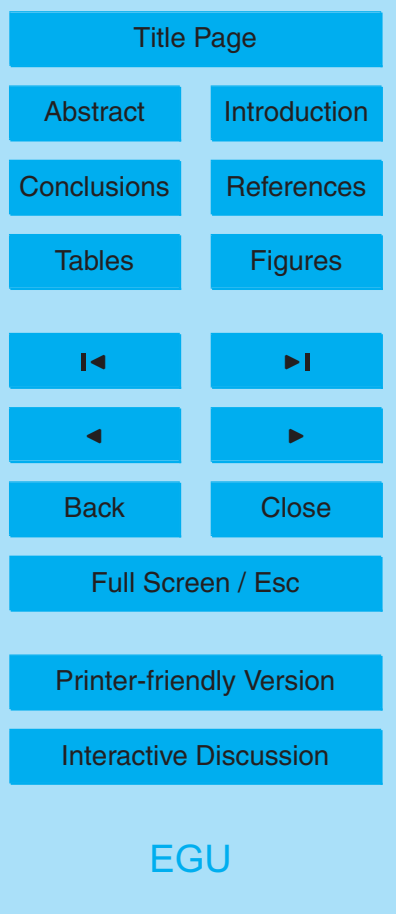


case, it would be an error to infer that the top of this early morning aerosol return marks the top of the mixing layer. The second feature is the rapid decrease in the maximum altitude of strong returns beginning about 16:00 LT (22:00 UTC). The zone of relatively clear air persisted for approximately $2 \mathrm{r}$. This was a common feature of afternoon 5 boundary layers in the lidar measurements. Although the tabulation of Fast et al. (2007) does not indicate deep convection on this day, we speculate that the upper boundary layer may have nevertheless been disturbed by smaller convective clouds that were common in the afternoons on most days.

While there are objective methods for calculating the top of the boundary layer from 10 lidar returns, such as finding the height of the maximum rate of decrease of returned signal (noted earlier), these methods often go astray when residual layers, convection, or other confounding features are present. As a result we have also subjectively selected mixing layer depths from the lidar. The white line in Fig. 3 represents our subjective assessment for 9 March. In contrast to our approach for the radiosondes, 15 we selected boundary layer depth from the lidar with some external information and assumptions. External information included the time of onset of convection from the sodar (see discussion below). We also assumed that beginning about the time of sunset, we could no longer infer that the presence of particulate scatterers implied an actively mixing layer. We did not, therefore, estimate boundary layer depth from the lidar after this time.

\subsubsection{Boundary layer depth from radar and sodar}

For wind profiling radars and sodars, the returned signal depends on small-scale variations in radio and acoustic refractive indices, respectively. (A good overview of the related physical principles can be found in Chadwick and Gossard, 1984 and Neff and

25 Coulter, 1984). For sodars, this is primarily a function of temperature, and for radars small-scale humidity variations are usually the dominant contributor. The refractive index variations are largest where turbulence interacts with strong mean gradients, which commonly occurs in the immediate vicinity of the surface and in the capping inversion.

The daytime mixing layer during MILAGRO

W. J. Shaw et al.

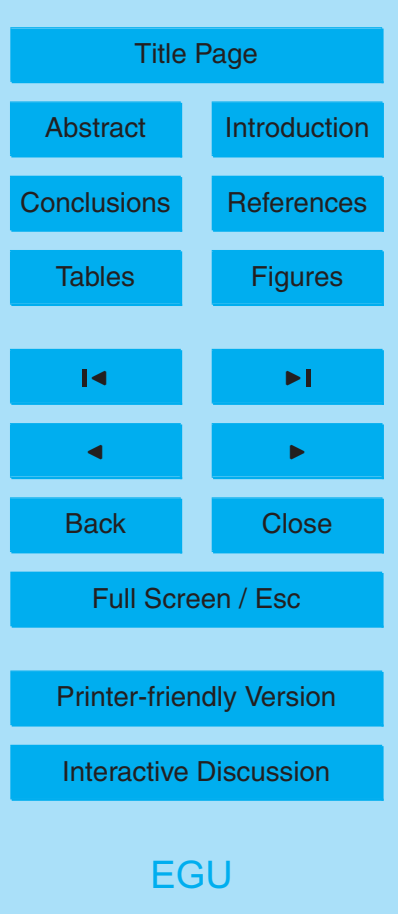


Therefore, the depth of the boundary layer is often inferred from radars and sodars as the midpoint of an elevated layer of strong return during the daytime or the top of the surface-based layer of significant return at night. Because mean gradients in $\theta$ and $q$ can also produce some return in the presence of even very weak turbulence, 5 inversions from preceding afternoons are often visible at night even though they are no longer connected to the surface through turbulent mixing.

Figure 4 shows a time-height cross section of reflectivity from the radar at T1 that illustrates these features. At 06:00 LT there was a layer of relatively strong radar return near $2000 \mathrm{~m}$ that gradually descended as the morning progressed. At approximately 10 08:00 LT, the onset of the convective boundary layer was detected by the sodar. By 09:30 the layer had deepened enough to be detected in the lowest range gates of the radar. The layer continued to grow until it reached a maximum altitude near $3500 \mathrm{~m}$ around 16:00 LT. In subjectively selecting mixing layer depths as a function of time, we have smoothed through what appear to be fluctuations in its depth of several hundred 15 meters over periods significantly less than an hour. Figure 3 shows similar fluctuations in the lidar signal. It is possible that these are gravity waves on the inversion, perhaps initiated by convection in the boundary layer.

We note that the MILAGRO data archive contains boundary layer depth estimates for the UAH radar in addition to the radar data themselves. However, because of the subjective nature of selecting these estimates from the backscatter, we have for consistency performed our own selection based on the range-corrected signal-to-noise ratio at T0. A comparison (not shown) between our values for mixing layer depth from the $\mathrm{UAH}$ radar and those in the MILAGRO data archive show that the archive values are consistently about $500 \mathrm{~m}$ lower than our selections for altitudes greater than about $1000 \mathrm{~m}$ a.g.l.

The sodar signal does not reach as high in the boundary layer as the radar, but it is very useful for measuring details of turbulence structure with relatively high vertical resolution in the lowest 100-200 m above the surface. It effectively fills the measurement gap between the wind profiler's lowest range gate and the surface. Figure 5 shows the

The daytime mixing layer during MILAGRO

W. J. Shaw et al.

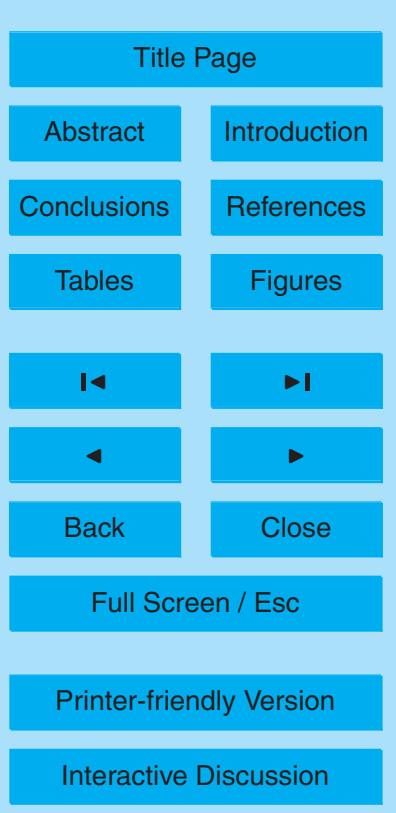

EGU 
time-height cross-section of range-corrected sodar backscatter at T1 from the same period as the profiler data in Fig. 4. From 12:00 UTC (06:00 LT) until about 14:00 UTC and from 00:00 UTC (18:00 LT) through the following night, the backscattered signal reflects the intermittent turbulence that is common in the nocturnal stable layer. While

5 sunrise occurred about 13:00 UTC, the onset of continuous, convective turbulence did not begin until between 14:00 and 14:30 UTC. The fine vertical resolution of the sodar allows the time of onset of convective turbulence to be identified fairly precisely. We have indicated the time of onset of convection based on this backscatter cross-section in Fig. 4.

10 We have shown selected boundary layer depths from the various instrument systems in Fig. 4. The lidar and the radar follow each other closely during the growth of the boundary layer in the morning. We have also indicated selections of boundary layer depth from the soundings, including alternate choices where those were made. The mixing layer depth from the first sounding at 09:00 LT matches the boundary layer depth from the sodar. The preferred selection from the 11:00 LT sounding matches the lidar and radar well, while the alternative boundary layer depth falls within the residual inversion from the preceding day. The selection from the 13:00 LT sounding was less successful. The primary choice from the radiosonde for boundary layer depth was too low, and the nearest of the two alternate choices was also lower than the other instruments by nearly $500 \mathrm{~m}$.

\subsubsection{General comparison of measurements of boundary layer depth}

Figure 6 shows a general comparison between observations of mixing layer depth from the radiosonde ascents and the profiler at $\mathrm{T} 1$. The observations have been segregated by time of day. There is some scatter, but the figure indicates that most selections of 25 boundary layer depth from the radiosondes fall within two profiler range gates of the profiler value $(385 \mathrm{~m})$. As expected, boundary layer depths from both the profiler and the radiosonde consistently increased during the day. The figure also shows the effects of ambiguity in the radiosonde profiles. Eight of the estimates also have indications of 15038

7, 15025-15065, 2007

The daytime mixing layer during MILAGRO

W. J. Shaw et al.

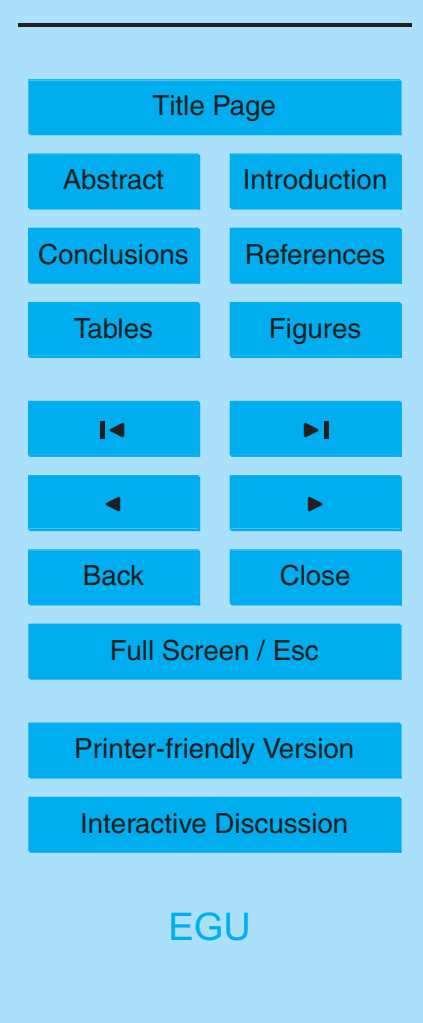


second choices for depth of the boundary layer as discussed above. In all of these cases, one or the other of the choices lies within two range gates of the profiler value.

A similar comparison between the lidar and the profiler at T1 is shown in Fig. 7. In general, the differences between boundary layer depth from these two systems is 5 significantly less than for the radiosonde-profiler comparison. The exception occurs at the end of the afternoon. The late afternoon is generally a period of decay of turbulence in the upper boundary layer, but as noted by Coulter (1979) this decay does not necessarily affect the distribution of particulate matter. As a result, a number of estimates of boundary layer depth from the lidar during this period were much greater 10 than the corresponding estimates from the profiler. The rms difference between the profiler and lidar values of mixing layer depth at $T 1$ is about $320 \mathrm{~m}$. If we exclude the hours after 14:00 LT, however, the rms difference between the two systems is about $220 \mathrm{~m}$. This is only slightly larger than a single profiler range gate and is less than $10 \%$ of the overall depth of the boundary layer for much of the daytime. The regression in the figure indicates that there is a slight overall tendency for the lidar to estimate a proportionally lower depth than the profiler. (An analysis of data presented by Cooper and Eichinger, 1994 shows that they observed a similar and somewhat larger tendency in a comparison between a lidar and radiosondes.) However, even at $4000 \mathrm{~m}$, this lower tendency is less than a single profiler range gate for our data. Thus the profiler and the lidar provided quite comparable measures of boundary layer depth during the daytime, especially prior to $14: 00$ LT.

These results are consistent with previous measurements of mixing layer depth. In a review of surface- based remote sensing, Wilczak et al. (1996) noted that the accuracy of measurement of boundary layer depth is limited by the range resolution of the instrument used. The effect of range resolution is illustrated by comparing our results with those of Beyrich and Görsdorf (1995), who compared a sodar and wind profiler to a maximum height of about $800 \mathrm{~m}$. The range resolution of the profiler in their case was $45 \mathrm{~m}$, and the rms difference between the two devices was $38 \mathrm{~m}$. In a more challenging comparison between wind profilers and an airborne lidar, White et al. (1999) found an

The daytime mixing layer during MILAGRO

W. J. Shaw et al.

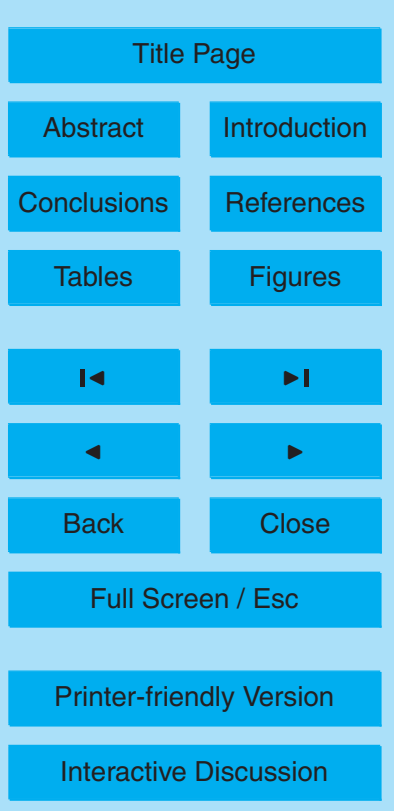

EGU 
rms difference between their systems of about $160 \mathrm{~m}$ with a profiler range resolution of $60 \mathrm{~m}$.

\section{Pattern of daytime convective mixing}

The daily onset of convective mixing on the Central Mexican Plateau is remarkably similar from day to day during the spring dry season. Using the same method as for the profiler, we have extracted the depth of the mixing layer in the early morning from the sodar at T1. Extrapolating the initial growth backward in time to the surface, it was possible to establish an onset time for the growth of the turbulent boundary layer each morning. Since the lowest range gate for the sodar was $15 \mathrm{~m}$ and since the convective boundary layer generally grew rapidly, the extrapolated onset was on the order of minutes before the first detection at $15 \mathrm{~m}$. Figure 8 shows the distribution of times relative to sunrise of the onset of convection in the morning at T1 for the entire campaign. For 17 of the 23 days of available measurements, the onset of convection occurred at $67.5 \pm 15 \mathrm{~min}$ after sunrise. Convection generally did not begin sooner than 45 min or later than 90 min after sunrise.

Figure 9 shows the daily evolution of mixing layer depth at T0, T1, and T2. Shaded areas in the figure indicate days for which Fast et al. (2007) tabulated isolated or scattered deep convection on the Central Mexican Plateau. There are several characteristics apparent from this figure. First, on most days the boundary layer growth in the morning was essentially the same at T1 and T2. This indicates that the more pronounced topographic variations at T2 did not appreciably affect boundary layer growth. Daily boundary layer growth was comparable at T0, although there was some tendency for its depth to be somewhat greater, especially later in the day. Second, the daily maximum boundary layer depth always reached $2000 \mathrm{~m}$ a.g.I. and occasionally exceeded $4000 \mathrm{~m}$. Thus, the top of the mixing layer commonly approached or exceeded the geopotential height of the $500 \mathrm{hPa}$ surface. Finally, the maximum depth of the boundary layer is not obviously related to whether deep convection developed on a given

The daytime mixing layer during MILAGRO

W. J. Shaw et al.

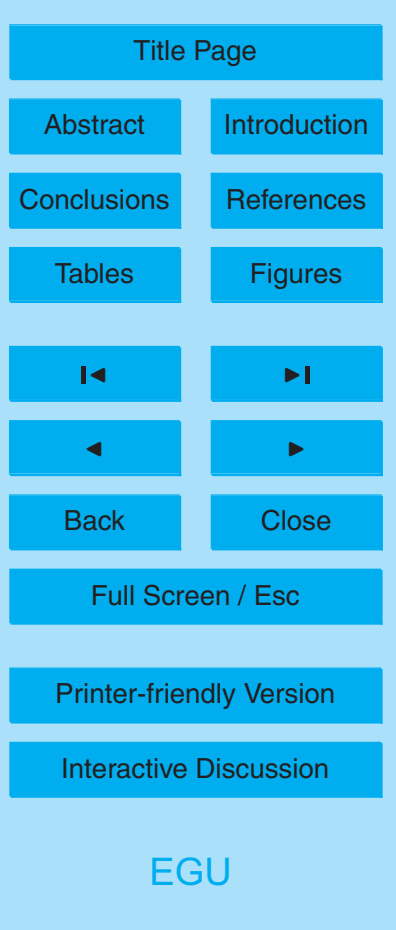


day.

Previous field campaigns in the Mexico City area have provided measurements of $A B L$ depth in approximately the same season as MILAGRO. In 1997 during the IMADA-AVER campaign (Doran et al., 1998), PNNL operated a wind profiler at Teoti5 huacán, which is approximately $15 \mathrm{~km}$ east of $\mathrm{T} 1$. Those data provide an opportunity to compare boundary layer evolution in nearly the same location for the same season in different years to see whether significant variations may occur from year to year. We have applied the same method described above to extract boundary layer depth from the profiler used at Teotihuacán in 1997. Figure 10 shows individual estimates of 10 mixing layer depth for all days binned by half-hour intervals. The lines connect median values of the estimates for each half hour. The figure shows that the median depth of the boundary layer was hardly distinguishable between the two years prior to 14:00 LT. In mid- to-late afternoon, the mixing layer was somewhat deeper during MILAGRO. The variability of mixing layer depth with time was also comparable between the campaigns.

15 At mid-morning for any particular day, the ABL was generally within about $500 \mathrm{~m}$ of the median value. This variability about the median approached $1000 \mathrm{~m}$ by late afternoon, although it was somewhat smaller during IMADA-AVER. These data suggest that the rate of $A B L$ growth on the Central Mexican Plateau falls within fairly predictable bounds, at least in the springtime.

\section{Humidity structure of the boundary layer}

We noted in the introduction that relative humidity is an important variable for understanding aerosol particle size distributions. Figure 11 provides a record of the relative humidity structure of the boundary layer as measured by radiosondes launched at T1 over the period of the campaign. As was the case in Fig. 9, which showed the growth of boundary layer depth at all three profiler sites, the gray shaded days are those for which Fast et al. (2007) indicated scattered or isolated deep convection at some point during the day. The general trend of dry ABLs during early part of the campaign and

The daytime mixing layer during MILAGRO

W. J. Shaw et al.

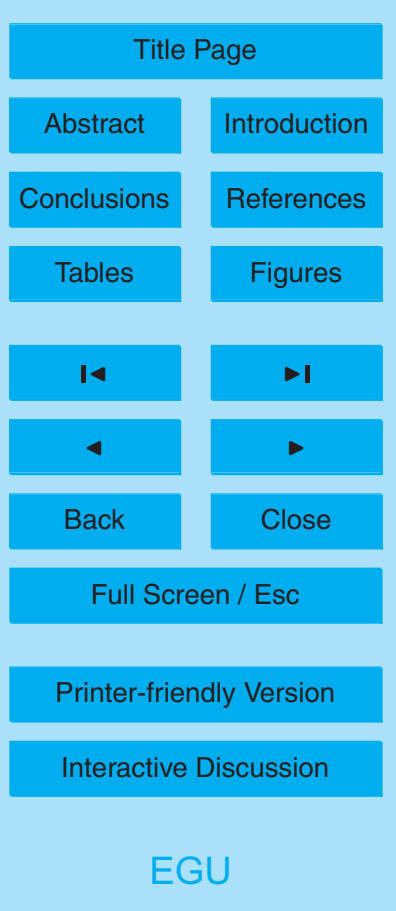


moister boundary layers later is reflected in the figure.

Figure 2 illustrated a typical humidity structure within and above the ABL. The mixing ratio within the boundary layer was nearly constant or decreased slowly with height owing to the active turbulent mixing that was present. For fair weather conditions, the

5 mixing ratio commonly dropped dramatically through the capping inversion, and the mixing ratio values were much lower in the free atmosphere above. As a result, relative humidity typically reached a maximum at the top of the boundary layer. This is evident for many of the days in Fig. 11, where maximum relative humidity values in each profile lie just below the curve that indicates the profiler-derived inversion height. On a majority 10 of days, these relative humidity values reached or exceeded $50 \%$, so that hygroscopic growth for aerosol particles within the upper boundary layer was likely.

The figure also shows another characteristic feature of convective boundary layer growth. The mean ABL relative humidity was frequently largest in the earliest sounding and decreased later in the day. Processes that generate this behavior include the 15 entrainment of drier air into the boundary layer from the free atmosphere as the ABL depth increases and the overall increase in mean temperature of the boundary layer resulting from surface heating. In the last days of the campaign (after 21 March), when deep convection became a more prominent feature, the local maximum of relative humidity at the top of the ABL was less pronounced. Drying within the boundary layer as 20 the day progressed still occurred, but surface values of relative humidity were generally higher.

\section{Winds in the boundary layer}

During the MILAGRO campaign, winds in the boundary layer on the Central Mexican Plateau reflected both the passage of large-scale weather systems described by Fast et al. (2007) and diurnal forcing of distinctive temporal and spatial variations. In their cluster analysis of winds in the Mexico City area, de Foy et al. (2007) found significant horizontal shear between T0 and T1. Spatial variations are of particular interest for

The daytime mixing layer during MILAGRO

W. J. Shaw et al.

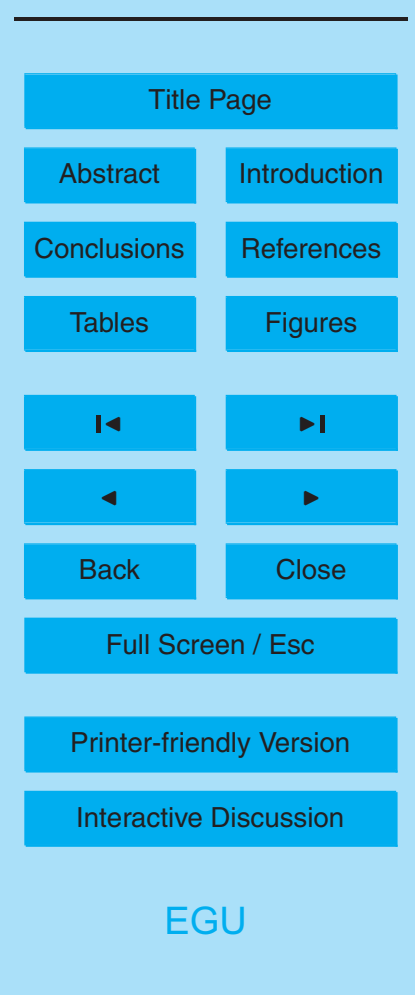


transport studies such as those described by Doran et al. (2007). In this description of $\mathrm{ABL}$ winds, we therefore include a comparison between the profilers at T1 and T2 as an indicator of horizontal variability within the boundary layer. The profiler at T1 was well removed from prominent local terrain features, while T2 was located about $50 \mathrm{~km}$ 5 away adjacent to the first foothills of the mountains to the north of Mexico City. Thus, this comparison is representative of the variability in ABL winds that may have been induced by the significant hills and mountains that surround the Mexican plateau.

Figure 12 includes a record of wind speed and direction measured approximately $600 \mathrm{~m}$ a.g.I. by the wind profiler at T1. This altitude was in the middle-to-lower bound10 ary layer during most of the day. The figure also shows wind speed and direction difference between T1 and T2 for the same altitude above ground at T2. A striking feature of the record is the strong diurnal pattern in wind speed that was especially prominent from the beginning of measurements through 13 March. During this period winds tended to be light during the late evening through mid- morning and then to increase 15 to a maximum that commonly exceeded $8 \mathrm{~m} \mathrm{~s}^{-1}$ in the late afternoon or early evening. This pattern persisted despite variations of wind direction from north-northeasterly (57 March) to southerly (8-11 March) to mainly northerly (12-13 March).

The pattern weakened but did not completely disappear with the onset of the first of three "Norte" events that occurred during the campaign (Fast et al., 2007). The 20 Norte is a surge of relatively cold air that occasionally spreads into the tropics from mid-latitudes. It is notable for the high winds generated at coastal locations such as Veracruz. Figure 12 indicates the periods of the three Norte events with dark shading. It is interesting that during all three events at T1 the typical diurnal cycle was suppressed, and late afternoon winds tented to be lighter than usual.

25 The diurnal cycle was also reflected in the differences between T1 and T2 at $600 \mathrm{~m}$ a.g.l. The wind speed difference $\left(\Delta S=S_{\mathrm{T} 1}-S_{\mathrm{T} 2}\right)$ is shown as the filled curve in Fig. 12. Thus, positive values of $\Delta S$ indicate that the wind speed at T1 was larger than at T2. In general, there was a tendency for the low-altitude winds to be larger at $\mathrm{T} 2$ than at $\mathrm{T} 1$, often by as much as $5 \mathrm{~m} \mathrm{~s}^{-1}$. However, there was also a diurnal cycle

The daytime mixing layer during MILAGRO

W. J. Shaw et al.

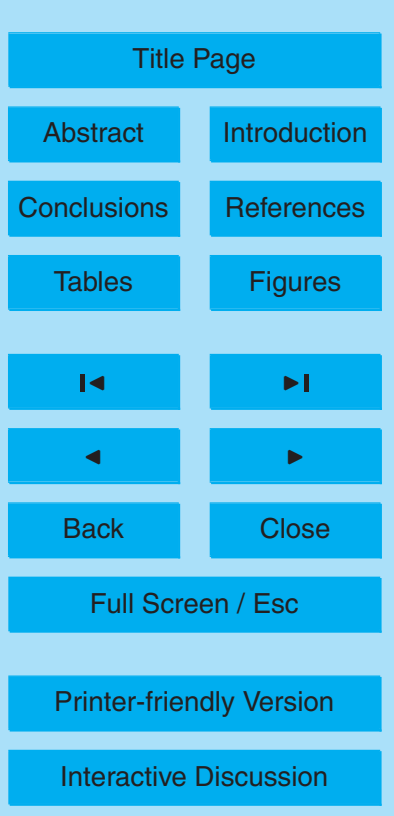

EGU 
in the wind speed differences. During the late afternoon, when wind speeds tended to be largest at T1, they were generally somewhat lighter at T2. Conversely, as the winds became relatively light overnight at $\mathrm{T} 1$, they remained stronger and sometimes even intensified at T2. This is a reflection of the diurnal cycle in wind speed being weaker at 5 T2 than at T1, despite the proximity of T2 to significant topographical relief.

The wind direction differences $\left(\Delta D I R=D I R_{\mathrm{T} 1}-D I R_{\mathrm{T} 2}\right)$ are not as systematic as those for wind speed. Figure 12 provides a colorbar indicator of the wind direction differences between $\mathrm{T} 1$ and $\mathrm{T} 2$. While this display does not provide a precise indication of the differences, it is a good visual indicator of periods during which differences were 10 strongly variable or were large. Color values near purple indicate relatively small differences, while orange, yellow, and green values indicate large direction differences. Not surprisingly, the figure shows that whenever winds were light at either station, the wind directions were strongly variable over short times intervals. Wind differences also tended to be large when significant temporal changes occurred over several hours in mean wind direction at $\mathrm{T} 1$, which suggests that many of these changes are associated with regional- rather than large-scale circulations. Finally, Fig. 12 also shows with light shading the days that Fast et al. (2007) tabulated as having scattered or isolated deep convection in the region during the day. Although not unique to these cases, the days that exhibited deep convection frequently also exhibited significant wind direction variability later in the day.

Figure 13 shows the same information as in Fig. 12, but for the profiler range gates centered at $1550 \mathrm{~m}$ a.g.I. Inspection of Fig. 10 shows that this altitude was typically within the mixing layer from approximately 12:00 LT until the cessation of convection sometime between 16:00 and 18:00 LT. Perhaps the most dramatic difference between the two figures is the absence at $1550 \mathrm{~m}$ of the diurnal maximum in wind speed at T1 in the early evening. A comparison of the two figures also shows that the early evening wind speed maximum at $600 \mathrm{~m}$ frequently exceeded the corresponding wind speed at $1550 \mathrm{~m}$. This is consistent with the findings of previous work that evening wind maxima in the region are often the result of a daytime coastal plain-to-plateau circulation (e.g.,

The daytime mixing layer during MILAGRO

W. J. Shaw et al.

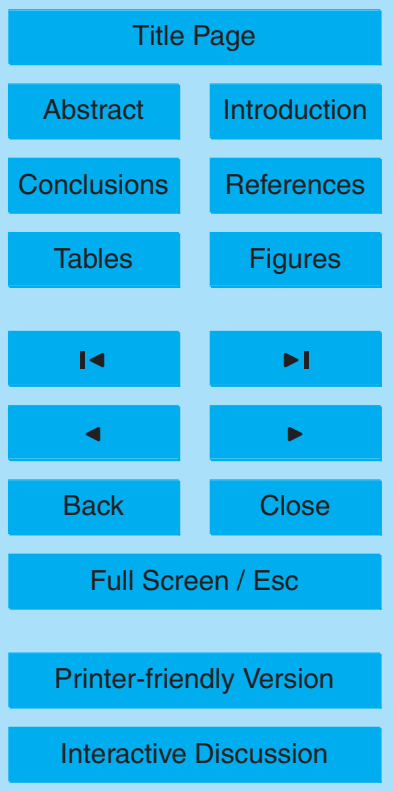


Bossert, 1997; Whiteman et al., 2000) or southerly gap flow (Doran and Zhong, 2000) that are in turn a result of the solar heating of the elevated plateau. The shallowness of the inflow layer, which individual time-height cross sections (not provided) show to be generally less than $1 \mathrm{~km}$ deep, suggests that relatively cool and dense lowland air is 5 drawn by this circulation onto the plateau, where it behaves much like a density current.

The wind direction was somewhat less variable and somewhat more westerly at $1550 \mathrm{~m}$ than nearer the surface, but it shows the same general directional variation over the course of the campaign. Another similarity between the two altitudes is that the wind speed was again higher more often at T2 than at T1. It is significant that 10 while this effect was present at all hours of the day, the two altitudes were linked via the mixing layer no more than $25 \%$ of the time. Moreover, the occurrence of higher wind speeds at T2 for both altitudes was less systematic for wind directions from the north to northeast but otherwise does not seem to have strongly depended on overall wind direction.

\section{Summary and conclusions}

In this paper we have compared boundary layer depths as determined from collocated radiosonde, wind profiler, and lidar systems during the 2006 MILAGRO field measurement campaign in the Mexico City region. There was no significant bias (with a caveat regarding the radiosonde system-see below) among the estimates of mixing layer depth from all three systems, and all three successfully measured boundary layers as deep as $4 \mathrm{~km}$ a.g.l. There were also, however, differences among the systems:

- Ambiguities in the selection of boundary layer depth from the radiosonde system, which was done without a priori reference to other measures, illustrates the value of having the temporal continuity provided by the profiler and lidar systems. Without the reference to other measurements to aid in resolving the ambiguities, there would have been a significant bias of the radiosonde measurement relative to the other systems in MILAGRO.

The daytime mixing layer during MILAGRO

W. J. Shaw et al.

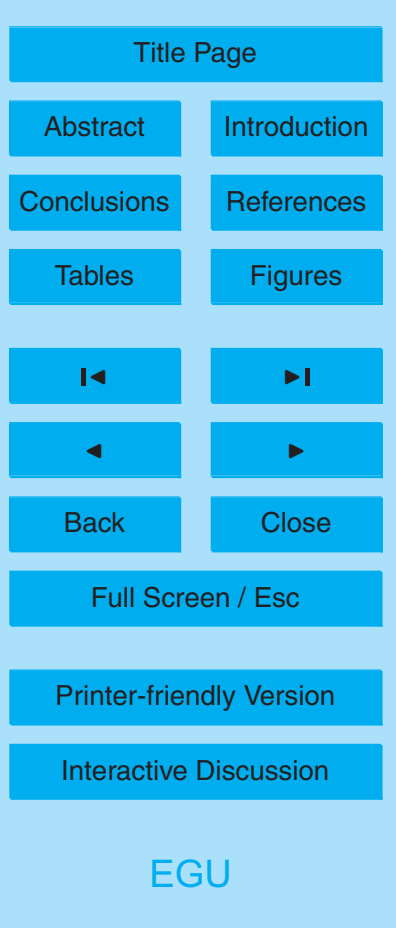


- The profiler and lidar systems showed no practical difference (within the resolution of the profiler range gates) in their measurements of boundary layer depth until mid-to-late afternoon. At that time, the decay of boundary layer turbulence led to occasionally much lower measurements of boundary layer depth from the profiler owing to the persisting particulate matter at higher altitudes.

- Our analysis suggests that because of its continuity in time and its response primarily to turbulence rather than mean variables, the profiler was more successful overall in establishing reliable mixing layer depths during the daytime in MILAGRO.

10 Because of its ability to fill in information between the surface and the lowest range gates of the profiler, the sodar was particularly useful in measuring the initial growth of the boundary layer in the morning. Its measurements revealed that the onset of mixing during MILAGRO began between $45 \mathrm{~min}$ and $90 \mathrm{~min}$ following sunrise, with the onset beginning in most cases about an hour afterward.

15 The multiple profilers afforded an opportunity to see what variability there was in mixing layer characteristics over the study region. In this regard, we make the following general observations:

- With only a few exceptions, the daily evolution of boundary layer depth was comparable at all three wind profiler locations. While the proximity to local terrain features did not seem to affect the depth at T2, there was a tendency for the boundary layer to be somewhat deeper at the TO site in central Mexico City.

- The mixing layer always reached a depth of $2000 \mathrm{~m}$ and frequently reached $4000 \mathrm{~m}$ a.g.l. during each afternoon in the campaign.

- The depth of the boundary layer was not obviously related to whether deep convection developed on a particular day.

- In comparing boundary layer growth at the T1 site with measurements made during the same season at Teotihuacán ( $15 \mathrm{~km}$ away) in 1997, we found the mean 15046

ACPD

7, 15025-15065, 2007

The daytime mixing layer during MILAGRO

W. J. Shaw et al.

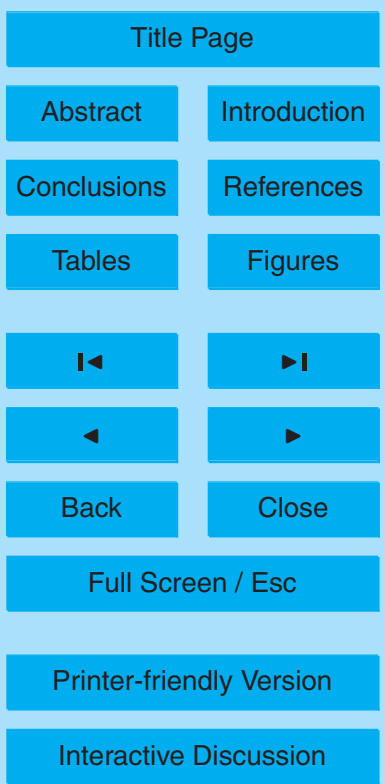

EGU 
daily growth of the boundary layer and its variability to be essentially identical. This suggests that defining a typical function relating boundary layer depth to time of day could be a useful efficiency for some atmospheric chemical or particulate models in this region and season.

5 The relative humidity structure of the boundary layer was systematically related to its daily growth, with maximum values generally observed as expected in the early morning and at the top of the mixing layer. Even on the drier days, it was common for the relative humidity to exceed $50 \%$ in upper portions of the boundary layer. It seems likely, therefore, that aerosol particles would have experienced some hygroscopic growth within the boundary layer on many days.

Winds also exhibited behavior within the boundary layer that may be taken to be characteristic:

- Relatively low-level wind speeds at T1 (600 m a.g.l.) exhibited a strong diurnal variability with a maximum speed occurring about 18:00 LT. This maximum was most pronounced early in the campaign, but it was observable on most days. It did not seem to be related to wind direction. A comparison with the wind speeds measured at T2 showed that the cycle was somewhat weaker at the same altitude, indicating that local wind forcing by terrain was not the mechanism.

- Wind speeds at $1500 \mathrm{~m}$ were lower and exhibited little of the diurnal variation of the lower altitudes. This is consistent with previous work that found that winds on the Central Mexican Plateau were driven by daily regional circulations.

- Three Norte events were dramatically experienced at Veracruz during the campaign. For these days on the plateau winds tended to be light and with a less prominent (or no) afternoon maximum in the speed. These events therefore did not seem to exert a significant effect on the winds measured in the Mexico City region other than, perhaps, to disrupt the regional circulations that generated the typical diurnal cycle.

The daytime mixing layer during MILAGRO

W. J. Shaw et al.

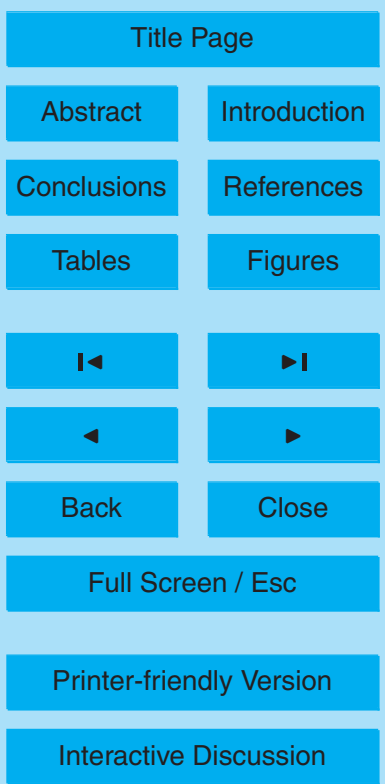

EGU 
This paper has provided a comprehensive description of the diurnal growth and variability of the atmospheric boundary layer observed during the MILAGRO campaign in the vicinity of Mexico City. We have found that the evolution of boundary layer depth was similar at the three profiler locations on the Central Mexican Plateau. The winds

5 were more spatially variable, however, indicating that horizontal transport was more complicated than the vertical mixing pattern. We believe that this work provides an important context for the interpretation of atmospheric chemical and aerosol processes that were measured concurrently, particularly with respect to dilution and hygroscopic effects.

10 Acknowledgements. We would like to thank Jerome Fast for helpful discussions and for supplying Fig. 1 of this paper. We also are grateful to P. Holowecky and J. Satola of Battelle for their assistance in making the field measurements. This research was supported by the U.S. DOE's Atmospheric Sciences Program of the Office of Biological and Environmental Research under Contract DE-AC06-76RLO 1830 at PNNL. Pacific Northwest National Laboratory is operated

15 for the U.S. DOE by Battelle Memorial Institute. Work at Argonne National Laboratory was supported under contract DE-AC02-06CH11357. The University of Alabama in Huntsville's MIPS participation in MILAGRO was supported by the National Science Foundation under Grant ATM-0552222.

\section{References}

Angevine, W. M., White, A. B., and Avery, S. K.: Boundary-layer depth and entrainment zone characterization with a boundary-layer profiler, Bound.-Layer Meteorol., 68, 375-385, 1994.

Berkowitz, C. M. and Shaw, W. J.: Airborne measurements of boundary layer chemistry during the Southern Oxidant Study: a case study, J. Geophys. Res., 102(D11), 12795-12804, 1997.

25 Beyrich, F. and Görsdorf, U.: Composing the diurnal cycle of mixing height from simultaneous sodar and wind profiler measurements, Bound.-Layer Meteorol., 76, 387-394, 1995.

Bianco, L. and Wilczak, J. M.: Convective boundary layer depth: improved measurement by Doppler radar wind profiler using fuzzy logic methods, J. Atmos. Ocean. Technol., 19, 17451758, 2002.

The daytime mixing layer during MILAGRO

W. J. Shaw et al.

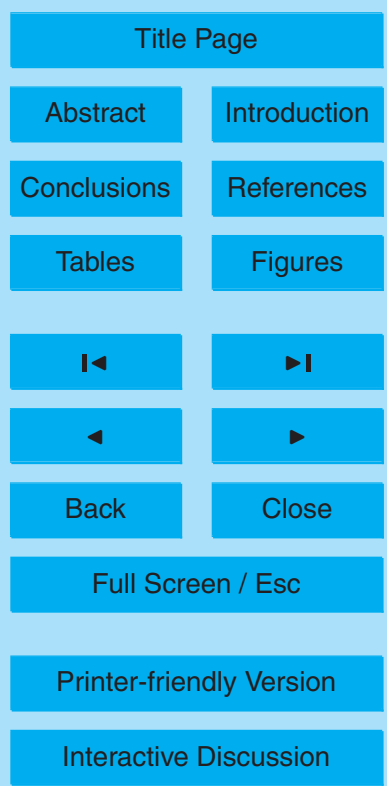

EGU 
Bossert, J. E.: An investigation of flow regimes affecting the Mexico City region, J. Appl. Meteorol., 36, 119-140, 1997.

Chadwick, R. B. and Gossard, E. E.: Radar probing and measurement of the planetary boundary layer: part I scattering from refractive index irregularities, in Probing the Atmospheric $5 \quad$ Boundary Layer, edited by: Lenschow, D. H., Am. Meteorol. Soc., 163-182, 1984.

Cooper, D. I. and Eichinger, W. E.:Structure of the atmosphere in an urban planetary boundary layer from lidar and radiosonde observations, J. Geophys. Res., 99(D11), 22 937-22 948, 1994.

Coulter, R. L.: A comparison of three methods for measuring mixing layer height, J. Appl. Meteorol., 18, 1495-1499, 1979.

Coulter, R. L. and Martin, T. J.: Results from a high power, high frequency sodar, Atmos. Res., 20, 257-270, 1986.

Doran, J. C., Abbott, J. L., Archuleta, J., Bian, X., Chow, J. C., Coulter, R. L., de Wekker, S. F. J., Edgerton, S. A., Fernandez, A., Fast, J. D., Hubbe, J. M., King, C. W., Langley, D., Leach, J. M., Lee, J. T., Martin, T. J., Martinez, D., Martinez, J. L., Mercado, G., Mora, V., Mulhearn, M., Pena, J. L., Petty, R., Porch, W. M., Russell, C., Salas, R., Shannon, J. D., Shaw, W. J., Sosa, G., Watson, J. G., Templeman, B., White, R., Whiteman, C. D., and Wolfe, D.: The IMADA-AVER boundary layer experiment in the Mexico City area, Bull. Am. Meteorol. Soc., 79, 2497-2508, 1998.

Doran, J. C., Barnard, J. C., Arnott, W. P., Cary, R., Coulter, R., Fast, J. D., Kassianov, E. I., Kleinman, L., Laulainen, N. S., Martin, T., Paredes-Miranda, G., Pekour, M. S., Shaw, W. J., Smith, D. F., Springston, S. R., and Yu, X.-Y.: The T1-T2 study: evolution of aerosol properties downwind of Mexico City, Atmos. Chem. Phys., 7, 1585-1598, 2007, http://www.atmos-chem-phys.net/7/1585/2007/.

Doran, J. C. and Zhong, S.: Thermally driven gap winds into the Mexico City basin, J. Appl. Meteorol. 39, 1330-1340, 2000.

Fast, J. D., Doran, J. C., Shaw, W. J., Coulter, R. L., and Martin, T. J.: The evolution of the boundary layer and its effect on air chemistry in the Phoenix area. J. Geophys. Res., 105(D18), 22 833-22 848, 2000.

30 Fast, J. D., de Foy, B., Avecedo Rosas, F., Caetano, e., Carmichael, G., Emmons, L., McKenna, D., Mena, M., Skamarock, W., Tie, X., Coulter, R. L., Barnard, J. C., Wiedinmyer, C., and Madronich, S.: A meteorological overview of the MILAGRO field campaigns, Atmos. Chem. Phys., 7, 2233-2257, 2007,

The daytime mixing layer during MILAGRO

W. J. Shaw et al.

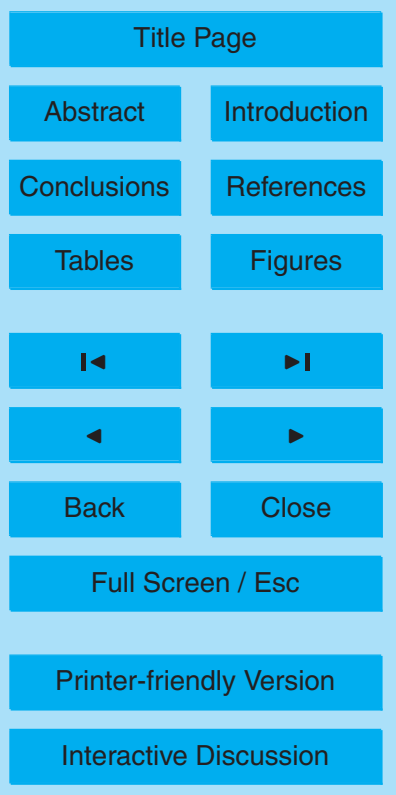


http://www.atmos-chem-phys.net/7/2233/2007/.

de Foy, B., Fast, J. D., Paech, S. J., Phillips, D. J., Walters, J. T., Coulter, R. L., Martin, T. J., Pekour, M. S., Shaw, W. J., Kastendeuch, P. P., Marley, N. A., Retama, A., and Molina, L. T.: Basin-scale wind transport during the MILAGRO field campaign and comparison to climatology using cluster analysis, Atmos. Chem. Phys. Discuss., 7, 13 035-13 076, 2007.

Grimsdell, A. W. and Angevine, W. M.: Convective boundary layer height measurement with wind profilers and comparison to cloud base, J. Atmos. Ocean. Technol., 15, 1331-1338, 1998.

Heo, B.-H., Jacoby-Koaly, S., Kim, K.-E., Campistron, B., Benech, B., and Jung, E.-S.: Use of the Doppler spectral width to improve the estimation of the convective boundary layer height from UHF wind profiler observations, J. Atmos. Ocean. Technol., 20, 408-424, 2003.

Holzworth, G. C.: Estimates of mean maximum mixing depths in the contiguous United States, Mon. Wea. Rev., 92, 235-242, 1964.

Holzworth, G. C.: Mixing depths, wind speeds, and air pollution potential for selected locations 15 in the United States, J. Appl. Meteorolog., 6, 1039-1044, 1967.

Juaregui, E.: Heat island development in Mexico City, Atmos. Environ., 31, 3821-3831, 1997.

Morse, C. S., Goodrich, R. K., and Cornman, L. B.: The NIMA method for improved moment estimation from Doppler spectra. J. Atmos. Ocean. Technol., 19, 274-295, 2002.

Neff, W. D. and Coulter, R. L.: Acoustic remote sounding, in Probing the Atmospheric Boundary Layer, edited by: Lenschow, D. H., Am. Meteorol. Soc., 201-235, 1984.

Seibert, P., Beyrich, F., Gryning, S.-E., Joffre, S., Rasmussen, A., and Tercier, P.: Review and intercomparison of operational methods for the determination of the mixing height, Atmos. Env., 34, 1001-1027, 2000.

Van Pul, W. A. J., Holtslag, A. A. M., and Swart, D. P. J.: A comparison of ABL heights inferred routinely from lidar and radiosondes at noontime, Bound.-Layer Meteorol., 68, 173-191, 1994.

White, A. B., Senff, C. J., and Banta, R. M.: A comparison of mixing depths observed by ground-based wind profilers and an airborne lidar, J. Atmos. Ocean. Technol., 16, 584-590, 1999.

so Whiteman, C. D., Zhong, S., Bian, X., Fast, J. D., and Doran, J. C.: Boundary layer evolution and regional-scale diurnal circulations over the Mexican basin, J. Geophys. Res., 105, 10081$10102,2000$.

Wilczak, J. M., Gossard, E. E., Neff, W. D., and Eberhard, W. L.: Ground-based remote sensing

The daytime mixing layer during MILAGRO

W. J. Shaw et al.

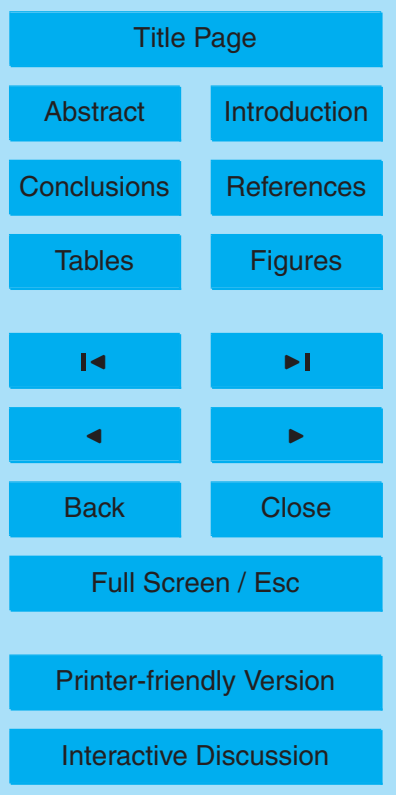


of the atmospheric boundary layer: 25 years of progress, Bound.-Layer Meteorol., 78, 321349, 1996.

\section{ACPD}

7, 15025-15065, 2007

The daytime mixing layer during MILAGRO

W. J. Shaw et al.

Title Page

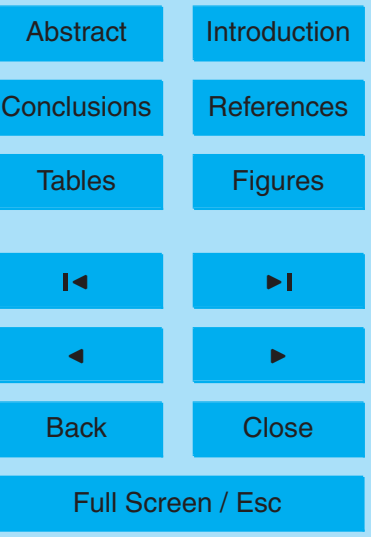

Printer-friendly Version

Interactive Discussion 
Table 1. Instruments that measured boundary layer properties at T0, T1, and T2 during the MILAGRO campaign.

\begin{tabular}{|c|c|c|c|c|c|}
\hline Instrument & Wavelength & $\begin{array}{l}\text { Minimum } \\
\text { Altitude }\end{array}$ & $\begin{array}{l}\text { Maximum } \\
\text { Altitude }\end{array}$ & $\begin{array}{l}\text { Vertical } \\
\text { Resolution }\end{array}$ & $\begin{array}{l}\text { Variables } \\
\text { Measured }\end{array}$ \\
\hline \multicolumn{6}{|c|}{ Instituto Mexicano del Petróleo (T0) } \\
\hline $\begin{array}{l}915 \mathrm{MHz} \\
\text { Wind Profiler }\end{array}$ & $33 \mathrm{~cm}$ & $131 \mathrm{~m}$ & $4075 \mathrm{~m}$ & $96 m$ & $\begin{array}{l}\text { SNR (from turbulence), } \\
\text { Winds }\end{array}$ \\
\hline \multicolumn{6}{|c|}{ Universidad de Tecámac (T1) } \\
\hline $\begin{array}{l}915 \mathrm{MHz} \\
\text { Wind Profiler }\end{array}$ & $33 \mathrm{~cm}$ & $206 \mathrm{~m}$ & $4825 m$ & $193 m$ & SNR, Winds \\
\hline Lidar & $573 \mathrm{~nm}$ & $15 \mathrm{~m}$ & $6000 \mathrm{~m}$ & $15 \mathrm{~m}$ & Signal strength (from aerosol) \\
\hline Sodar & $4500 \mathrm{~Hz}$ & $15 \mathrm{~m}$ & $200 \mathrm{~m}$ & $5 \mathrm{~m}$ & Winds, SNR (from turbulence) \\
\hline Radiosonde & $\mathrm{N} / \mathrm{A}$ & Surface & $>200 \mathrm{mb}$ & $3-5 m$ & $\begin{array}{l}\text { Pressure, temperature, rela- } \\
\text { tive humidity }\end{array}$ \\
\hline \multicolumn{6}{|c|}{ Rancho la Bisnaga (T2) } \\
\hline $\begin{array}{l}915 \mathrm{MHz} \\
\text { Wind Profiler }\end{array}$ & $33 \mathrm{~cm}$ & $206 \mathrm{~m}$ & $4825 m$ & $193 m$ & SNR, Winds \\
\hline Radiosonde & $\mathrm{N} / \mathrm{A}$ & Surface & $>200 \mathrm{mb}$ & $3-5 m$ & $\begin{array}{l}\text { Pressure, temperature, rela- } \\
\text { tive humidity }\end{array}$ \\
\hline
\end{tabular}

7, 15025-15065, 2007

The daytime mixing layer during MILAGRO

W. J. Shaw et al.

Title Page

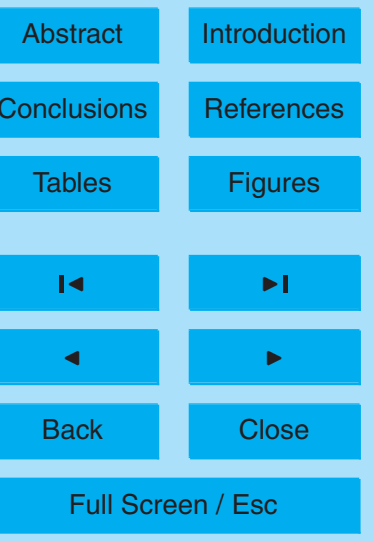

Printer-friendly Version

Interactive Discussion 


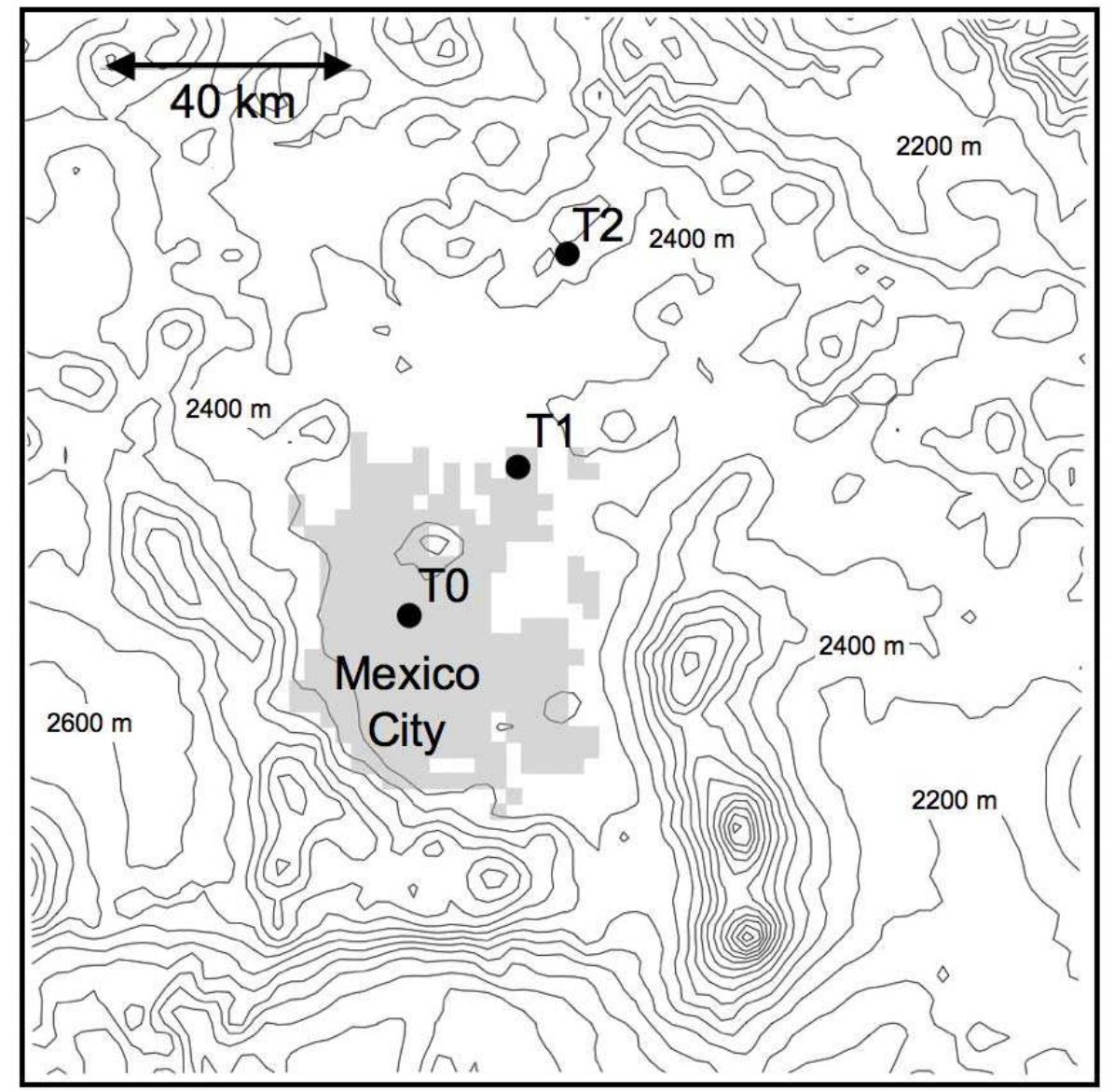

Fig. 1. The Central Mexican Plateau showing the locations of the three measurement sites whose data are reported in this paper.

\section{ACPD}

7, 15025-15065, 2007

The daytime mixing layer during MILAGRO

W. J. Shaw et al.

Title Page

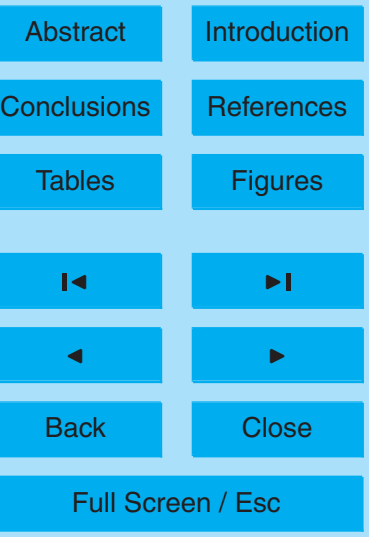

Printer-friendly Version

Interactive Discussion 


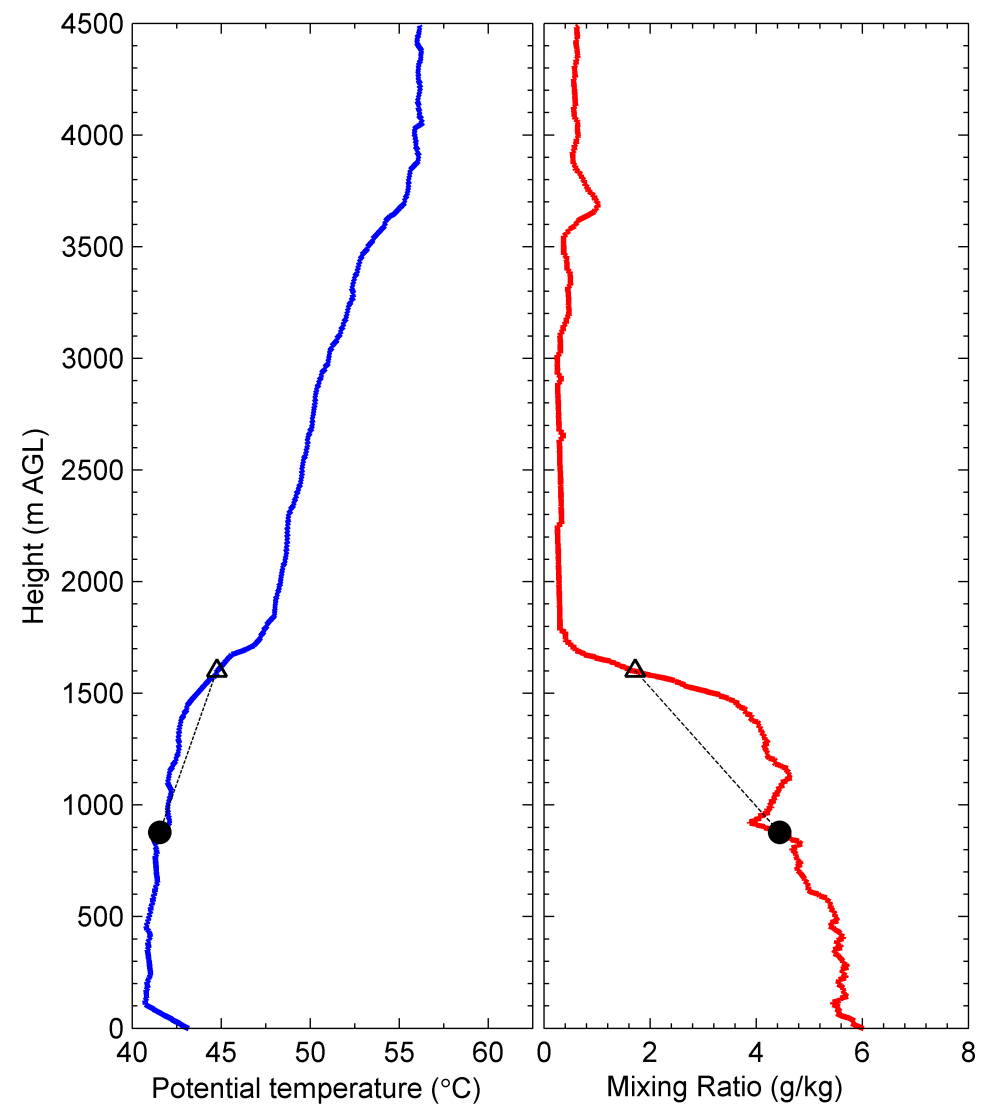

\section{ACPD}

7, 15025-15065, 2007

The daytime mixing layer during MILAGRO

W. J. Shaw et al.

Title Page

Abstract

Conclusions

Tables

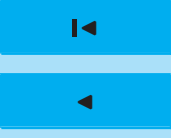

Back
Introduction

References

Figures

$\rightarrow$

$>$

Close

\section{Full Screen / Esc}

Printer-friendly Version

Fig. 2. Example radiosonde profiles of potential temperature and mixing ratio measured at T1 Interactive Discussion in selecting boundary layer depth. Our a priori selection for boundary layer depth for this case is indicated by the solid dot. The triangle indicates the secondary choice. 


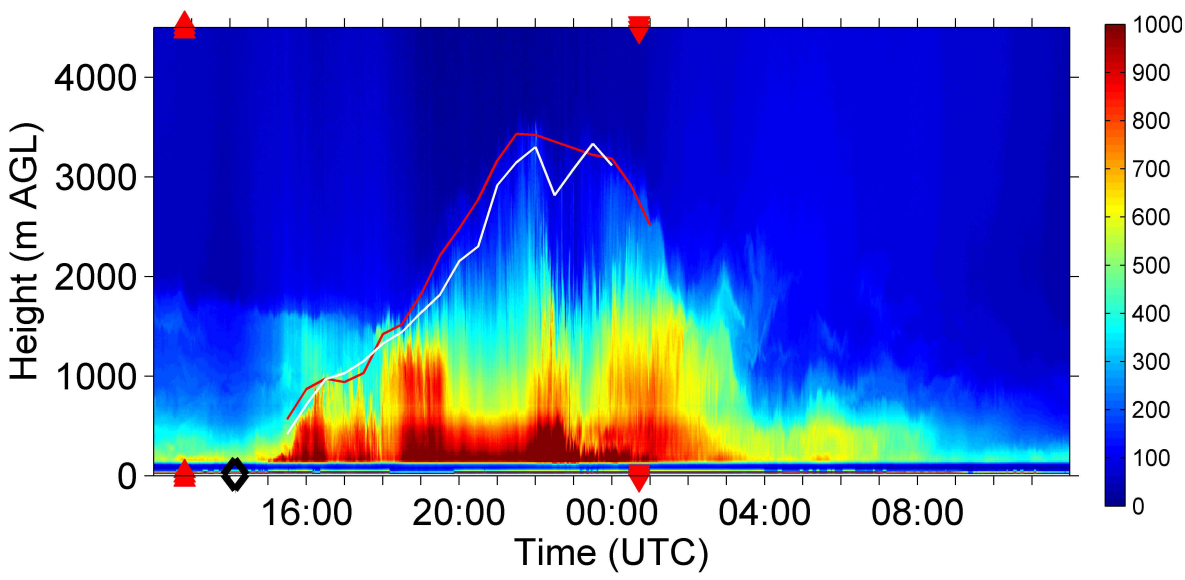

Fig. 3. Time-height cross-section of backscattered signal strength for the lidar at T1. The white curve is the subjectively determined estimate for mixing layer depth from the lidar on 9 March 2006. For comparison, the red curve is the same quantity derived separately from the wind profiler. Solid triangles on the abscissa are sunrise and sunset, and the open diamond indicates the onset of turbulence as determined from the sodar. Colorbar units are relative, with warmer colors indicating greater signal strength, and times are UTC.
The daytime mixing layer during MILAGRO

W. J. Shaw et al.

Title Page

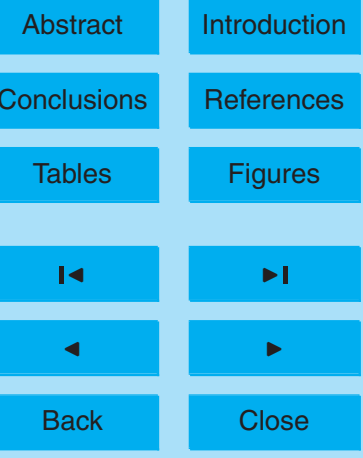

Full Screen / Esc

Printer-friendly Version

Interactive Discussion 


\section{ACPD}

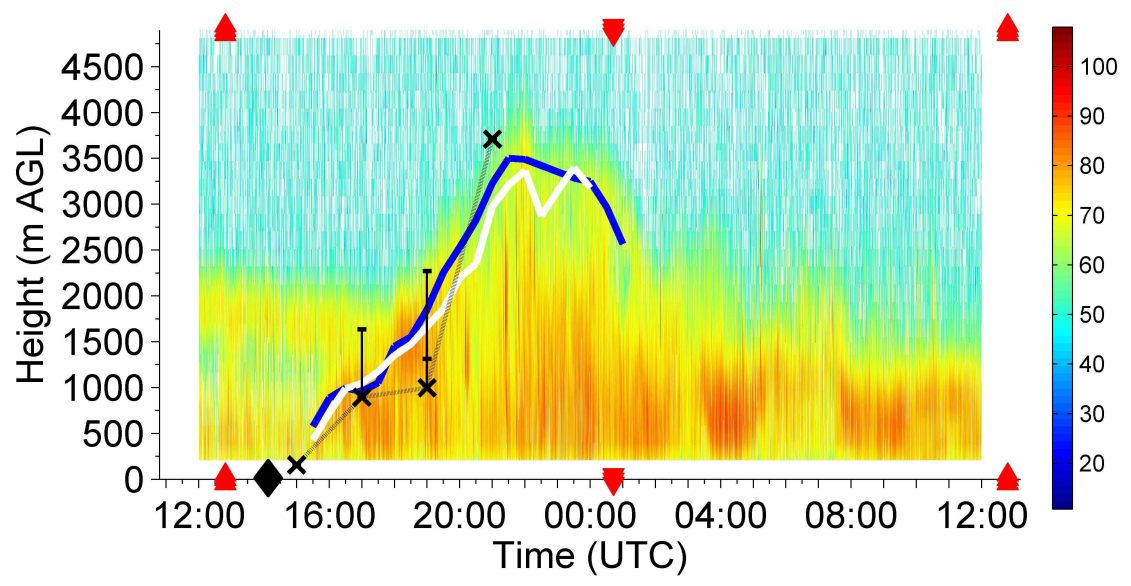

Fig. 4. Time-height cross section of profiler signal-to-noise ratio for 9 March 2006 together with estimates of boundary layer depth from the profiler based on these data (red line) and estimates from the lidar (white line) and radiosondes. For the radiosondes the "X" values are the a priori preferred choice, and the horizontal ticks are second and, occasionally, third choices for mixing layer depth. Note that the preferred choice for the radiosonde at 13:00 LT (19:00 UTC) turned out to be significantly lower than the lidar and sodar indicated.
The daytime mixing layer during MILAGRO

W. J. Shaw et al.

\section{Title Page}

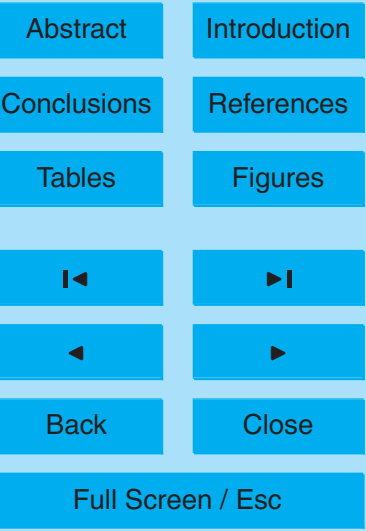

Printer-friendly Version

Interactive Discussion 


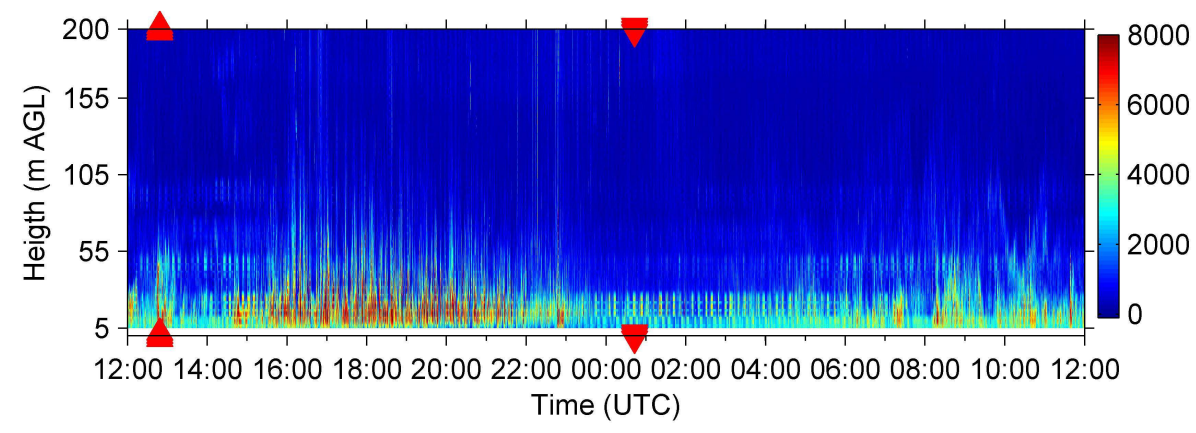

Fig. 5. Backscattered signal strength from the sodar for 9 March 2006. Nighttime intermittent turbulence is visible in the return from 12:00 UTC until about 14:30 UTC. The onset of daytime convective turbulence began between 14:30 and 15:00 UTC. Sunrise and sunset are indicated by the upward- and downward-pointing solid triangles, respectively.
ACPD

7, 15025-15065, 2007

The daytime mixing

layer during

MILAGRO

W. J. Shaw et al.

Title Page

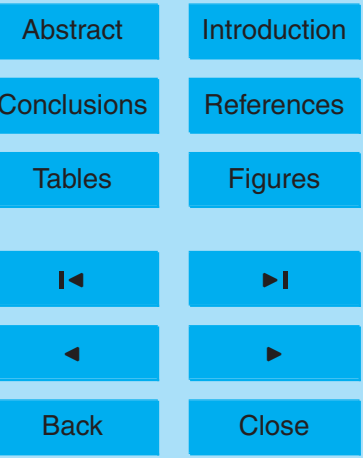

Full Screen / Esc

Printer-friendly Version

Interactive Discussion 


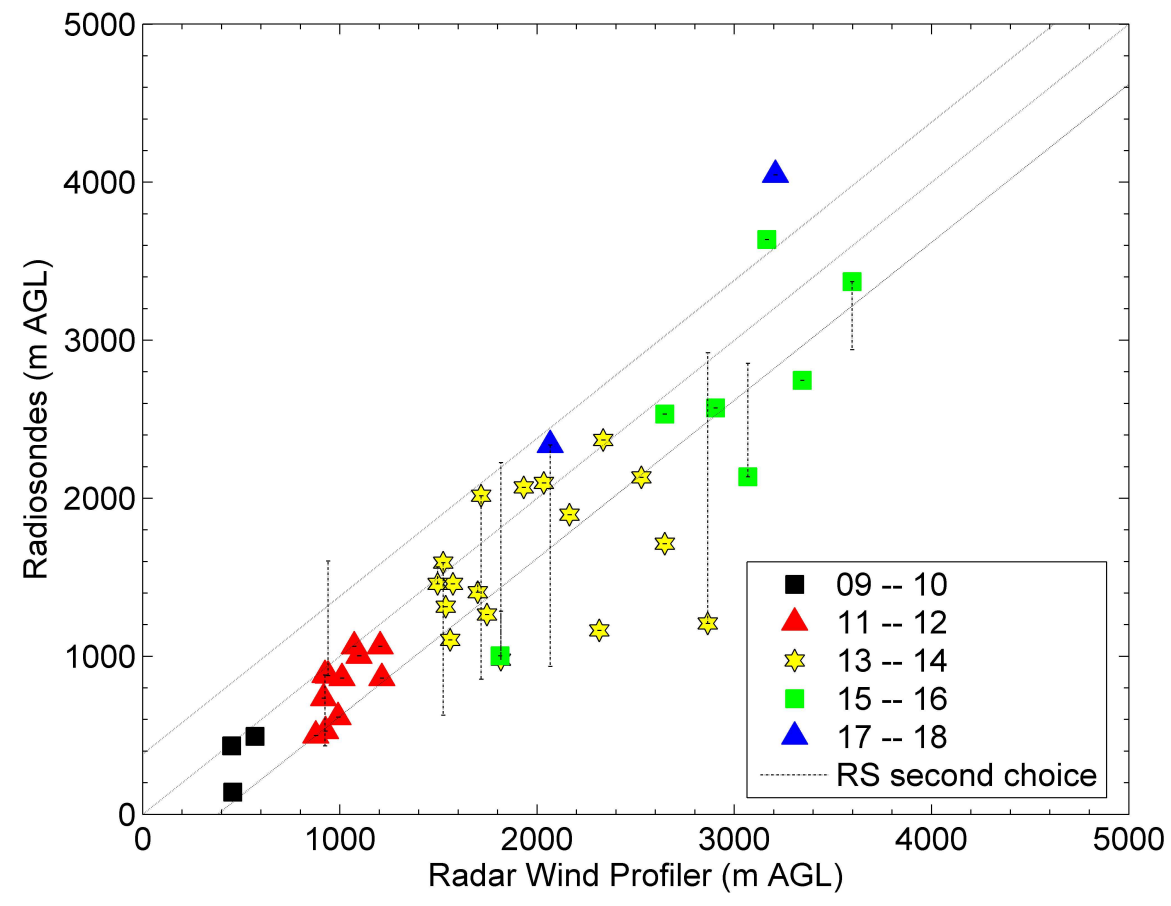

Fig. 6. Comparison of estimates of mixing layer depth between the wind profiling radar and all radiosonde ascents at $\mathrm{T} 1$, segregated by time of day (LT). Symbols indicate a priori preferred selections from the radiosonde ascents, and vertical lines end at alternate choices. Lines parallel to the $1: 1$ line represent an altitude difference of two profiler range gates.
ACPD

7, 15025-15065, 2007

The daytime mixing layer during MILAGRO

W. J. Shaw et al.

Title Page

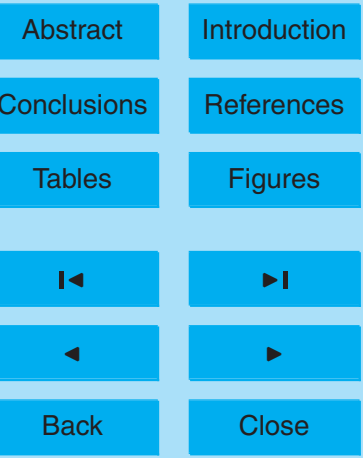

Full Screen / Esc

Printer-friendly Version

Interactive Discussion 


\section{ACPD}

7, 15025-15065, 2007

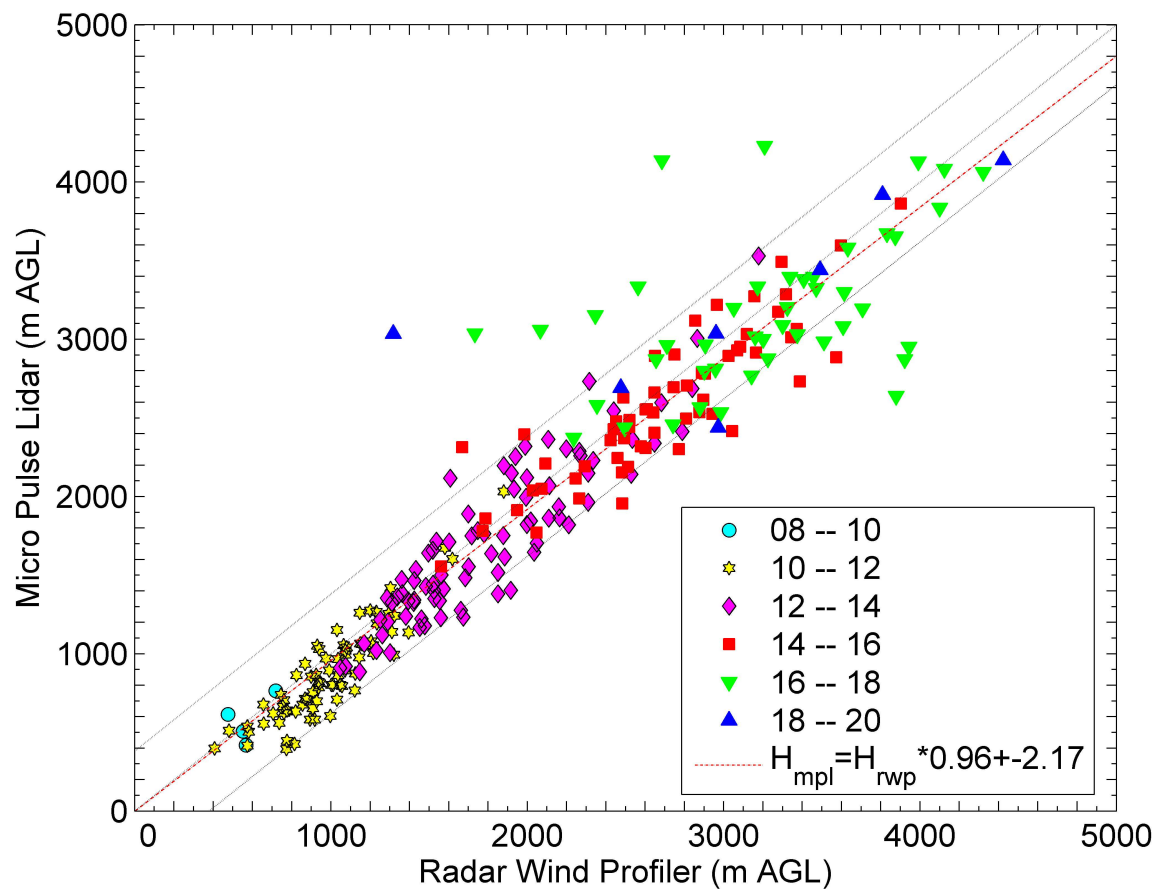

The daytime mixing layer during MILAGRO

W. J. Shaw et al.

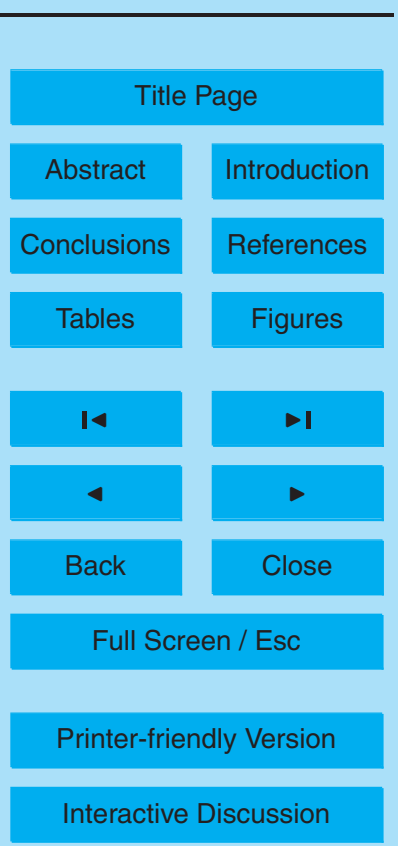

Fig. 7. As in Fig. 6, but for the lidar and the wind profiler at T1. The best-fit line, whose function is given in the legend, shows that there is little systematic difference between the two systems. 


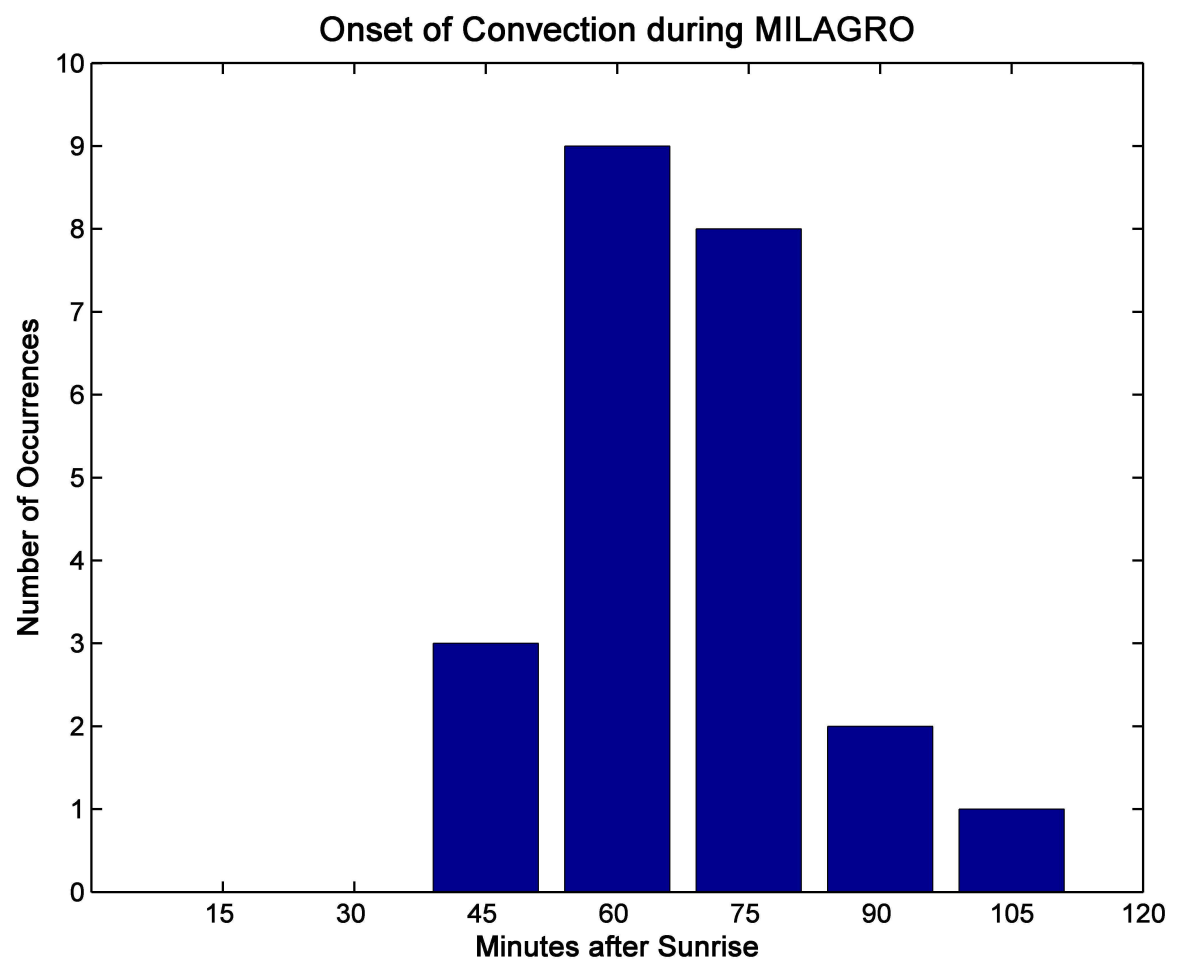

7, 15025-15065, 2007

The daytime mixing layer during MILAGRO

W. J. Shaw et al.

Title Page

Abstract

Conclusions

Tables

14

4

Back
Introduction

References

Figures

$>1$

$>$

Close

Full Screen / Esc

Printer-friendly Version

Interactive Discussion 


\section{ACPD}

7, 15025-15065, 2007
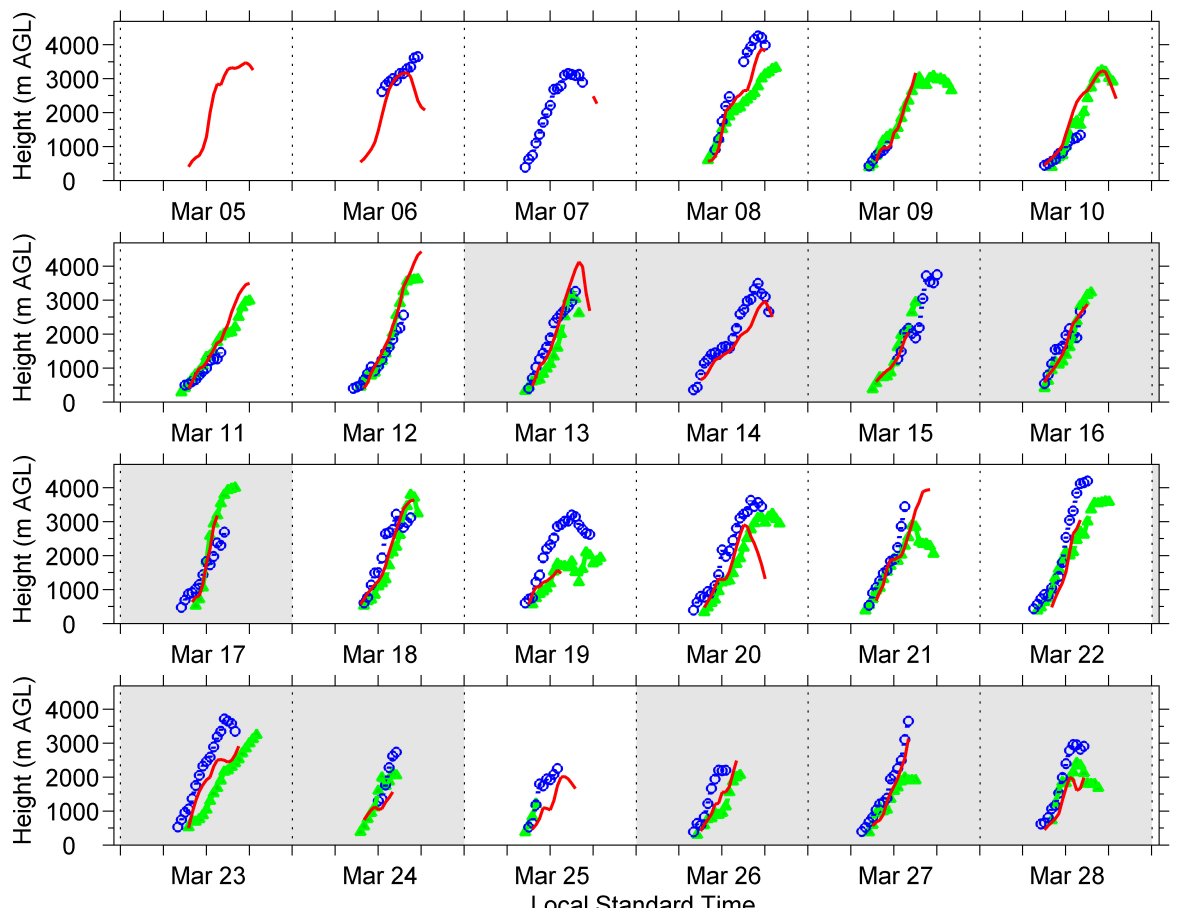

Fig. 9. Daily evolution of mixing layer depth at T0 (blue circles), T1 (red line), and T2 (green triangles). Days with shading are those for which Fast et al. (2007) reported scattered or isolated deep convection during the day.

The daytime mixing layer during MILAGRO

W. J. Shaw et al.

\section{Title Page}

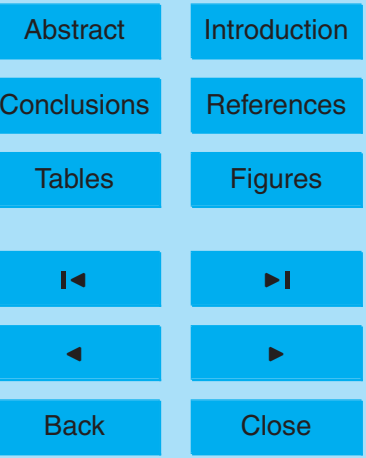

Full Screen / Esc

Printer-friendly Version

Interactive Discussion 


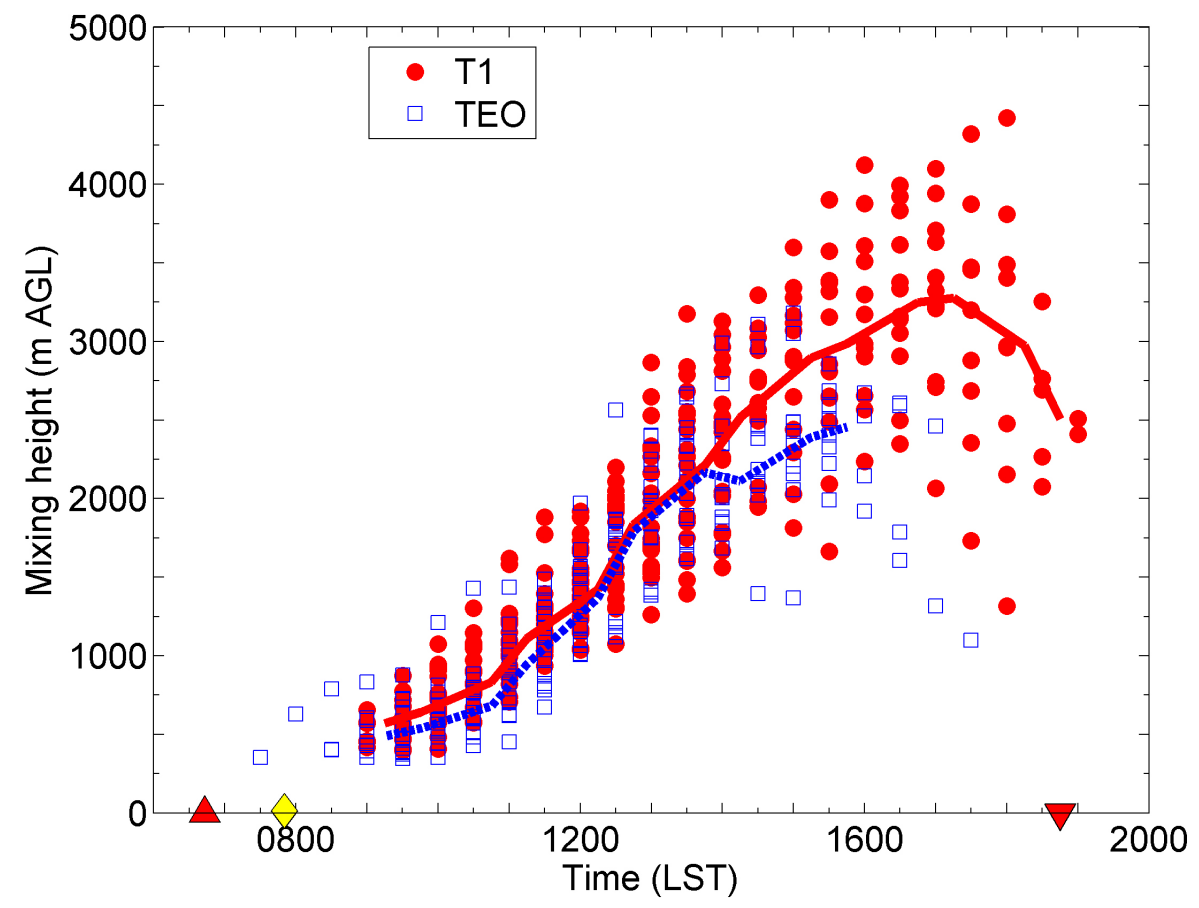

7, 15025-15065, 2007

The daytime mixing layer during MILAGRO

W. J. Shaw et al.

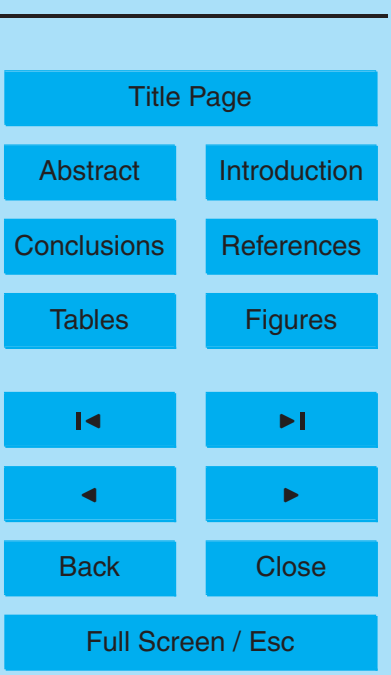

Fig. 10. Diurnal growth of the mixing layer during MILAGRO (red circles and line) and IMADA-
AVER in 1997 (blue squares, broken line). The lines connect median values for each half-hour time interval. Triangles on the abscissa represent average time of sunrise and sunset during the campaigns, and the yellow diamond is the average time of onset of convection.

Printer-friendly Version

Interactive Discussion 

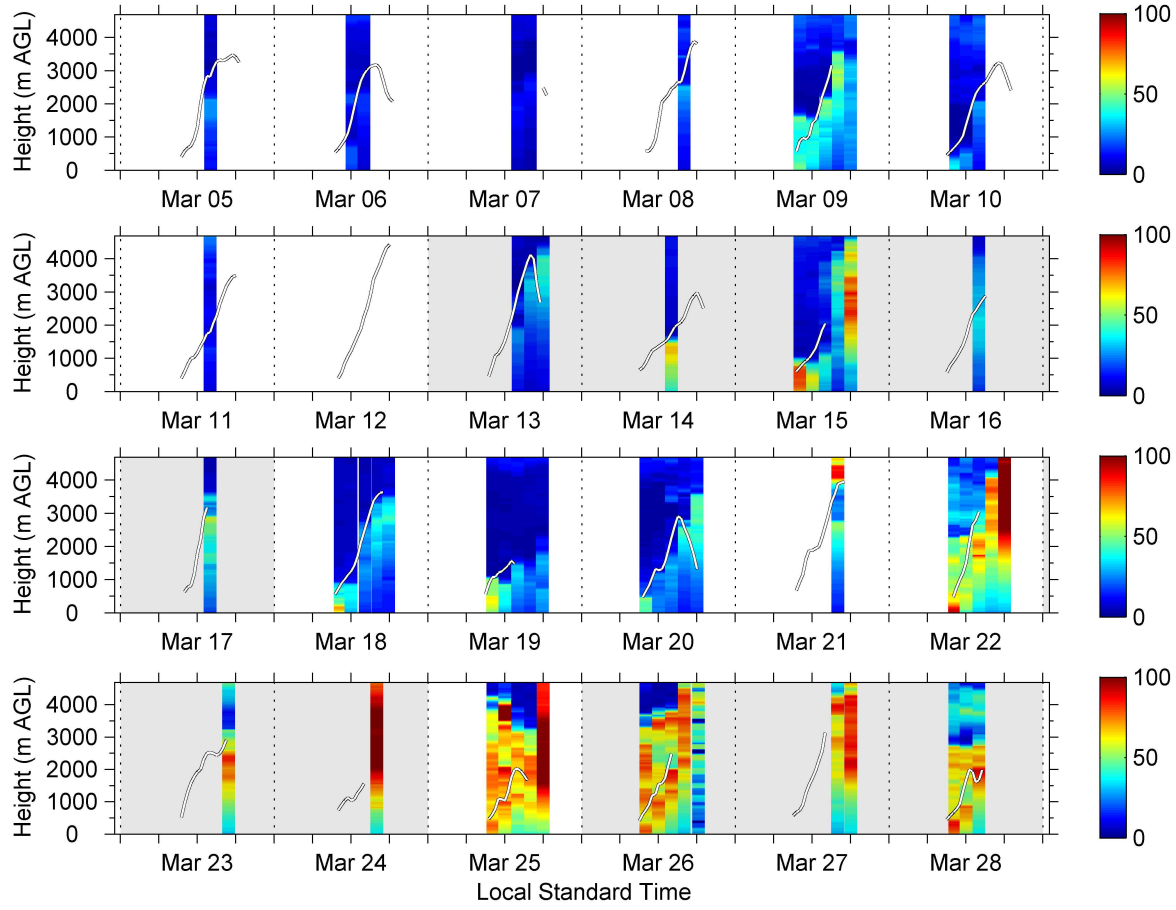

Fig. 11. Daily evolution of boundary layer percentage relative humidity during MILAGRO as measured at $\mathrm{T} 1$. The curves on each day are the mixing layer depth as measured by the profiler, and shaded areas are as in Fig. 9.
ACPD

7, 15025-15065, 2007

The daytime mixing layer during MILAGRO

W. J. Shaw et al.

Title Page

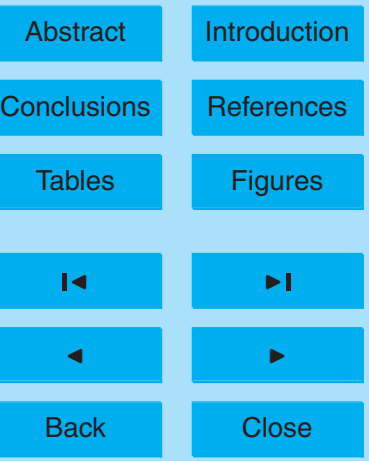

Full Screen / Esc

Printer-friendly Version

Interactive Discussion 


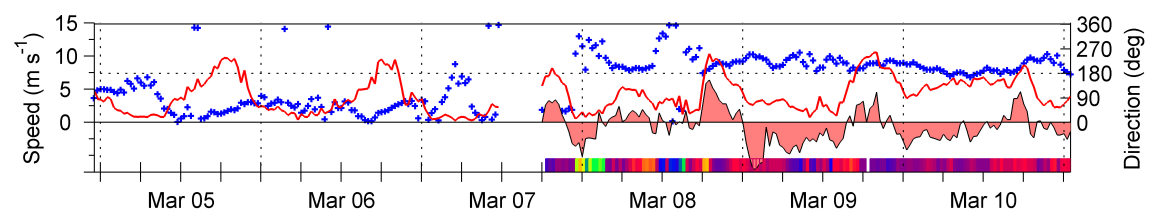

\section{ACPD}

7, 15025-15065, 2007
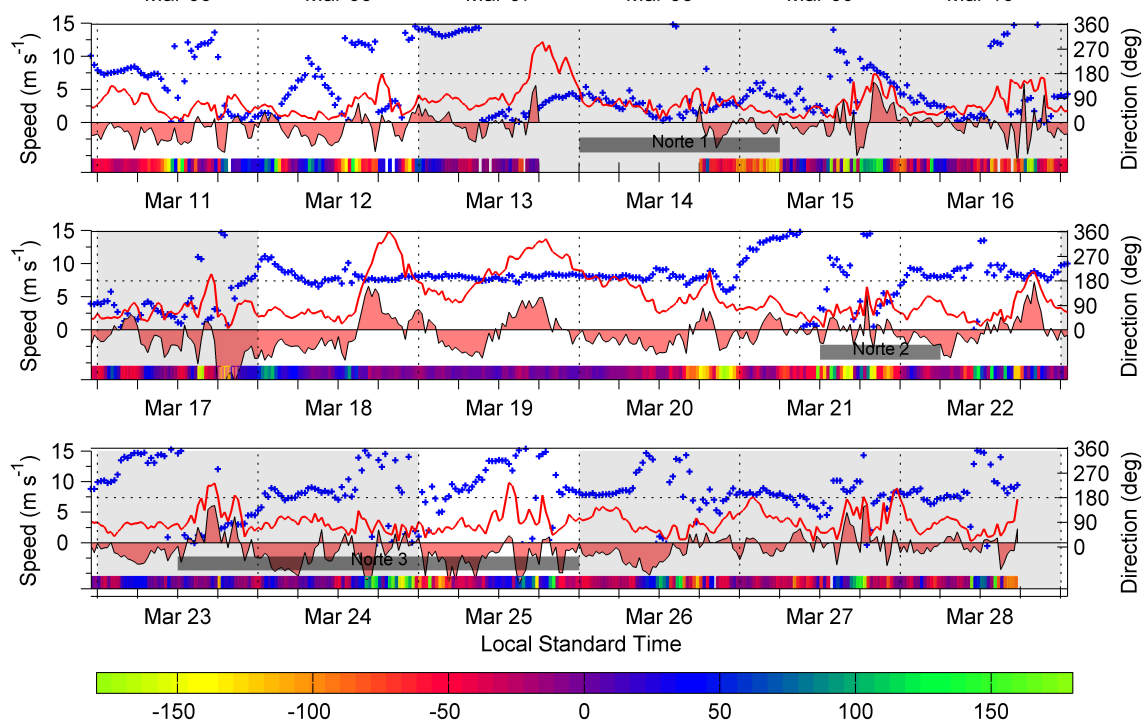

The daytime mixing layer during MILAGRO

W. J. Shaw et al.

Title Page

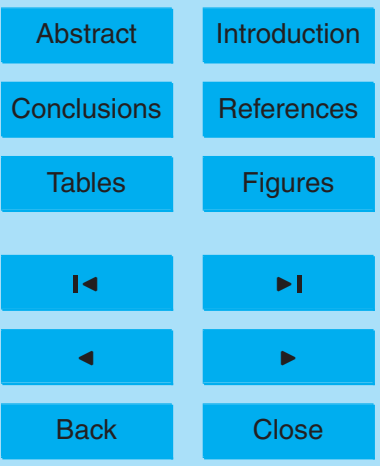
as measured by the wind profiler at T1. The filled curve is the wind speed difference between T1 and T2; the colored bar in each time series segment is the wind direction difference between the sites. The direction difference is \pm 180 deg according to the color scale at the bottom of the figure. Days with reports of deep convection are shaded light gray, and the three Norte events are indicated by dark gray bars.

\section{Full Screen / Esc}

Printer-friendly Version

Interactive Discussion 


\section{ACPD}

7, 15025-15065, 2007
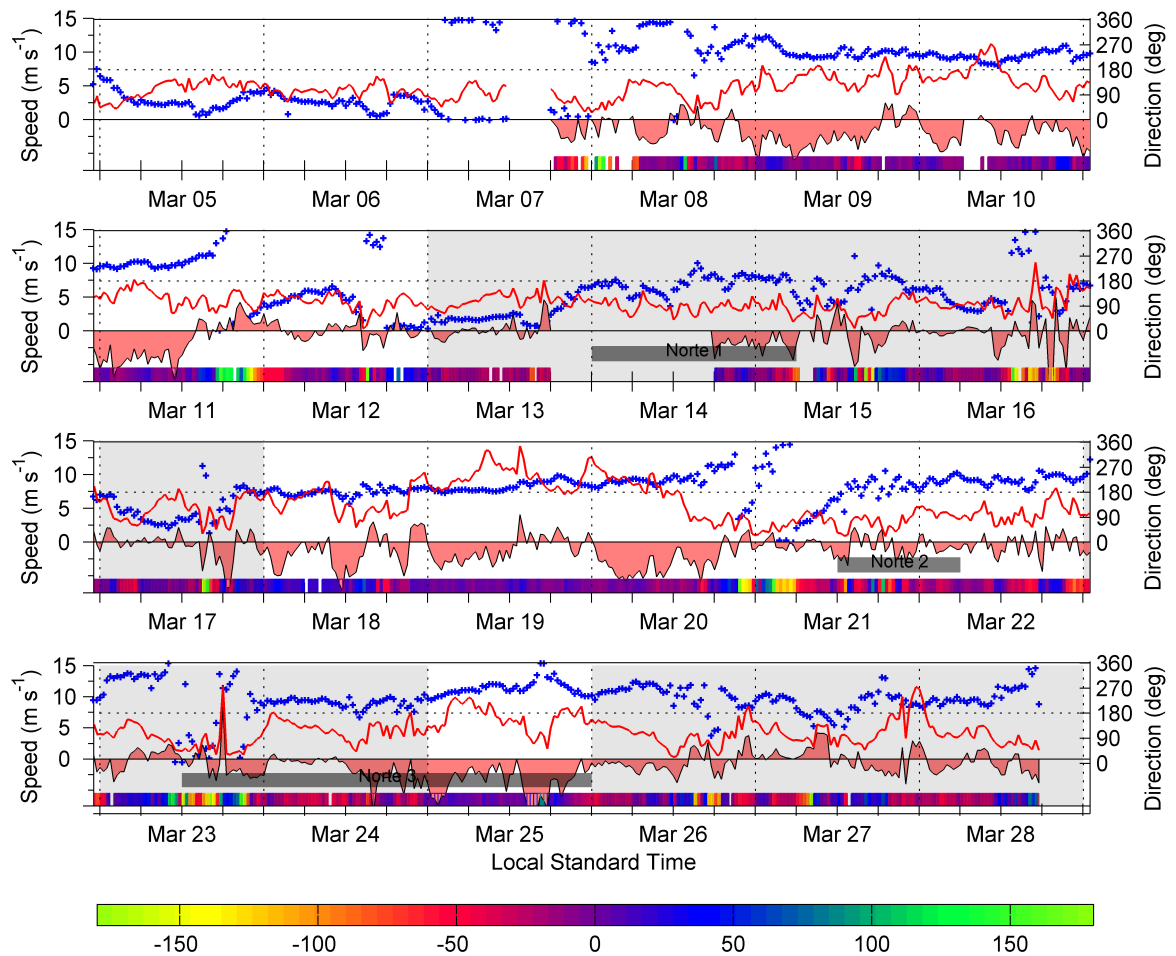

\section{The daytime mixing} layer during MILAGRO

W. J. Shaw et al.

\section{Title Page}

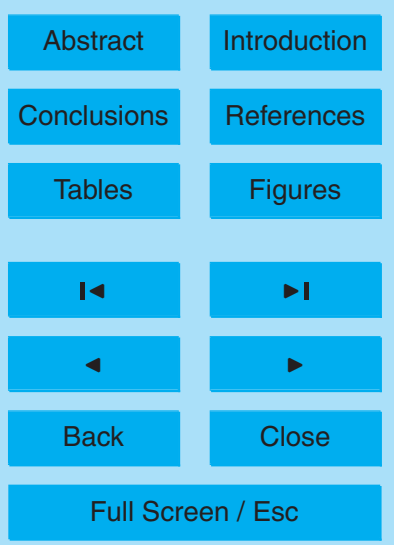

Fig. 13. As in Fig. 12, but for $1550 \mathrm{~m}$ a.g.l.

Printer-friendly Version

Interactive Discussion 